\title{
Unsaturated soils: From constitutive modelling to numerical algorithms
}

\author{
Daichao Sheng ${ }^{\mathrm{a}, *}$, Antonio Gens ${ }^{\mathrm{b}}$, Delwyn G. Fredlund ${ }^{\mathrm{c}}$, Scott W. Sloan ${ }^{\mathrm{a}}$ \\ ${ }^{a}$ Centre for Geotechnical and Materials Modelling, The University of Newcastle, Australia \\ ${ }^{\mathrm{b}}$ Department of Geotechnical Engineering and Geosciences, Technical University of Catalonia, Barcelona, Spain \\ ${ }^{\mathrm{c}}$ Golder Associates Ltd., Saskatoon, SK, Canada
}

\section{A R T I C L E I N F O}

\section{Article history:}

Available online 30 September 2008

\section{Keywords:}

Unsaturated soils

Constitutive modelling

Numerical algorithms

\begin{abstract}
A B S T R A C T
This paper presents an overview of constitutive modelling of unsaturated soils and the numerical algorithms for solving the associated boundary value problems. It first discusses alternative stress and strain variables that can be used in constitutive models for unsaturated soils. The paper then discusses the key issues in unsaturated soil modelling and how these issues can be incorporated into an existing model for saturated soils. These key issues include (1) volumetric behaviour associated with saturation or suction changes; (2) strength behaviour associated with saturation and suction changes, and (3) hydraulic behaviour associated with saturation or suction changes. The paper also shows how hysteresis in soil-water characteristics can be incorporated into the elasto-plastic framework, leading to coupled hydro-mechanical models. Finally, the paper demonstrates the derivation of the incremental stress-strain relations for unsaturated soils and discusses briefly the new challenges in implementing these relations into the finite element method.
\end{abstract}

(c) 2008 Elsevier Ltd. All rights reserved.

\section{Introduction}

All soils can be unsaturated with respect to water. In this regard, unsaturated soils are nothing special. However, the first fifty years of soil mechanics history have been primarily concerned with soils saturated with water and most soil mechanics principles developed in that period apply to saturated soils only. This shortcoming is actually one of the main driving forces for the emerging subject of unsaturated soil mechanics. Another important driving force is due to the distinct volume, strength and flow characteristics of certain soils when they become unsaturated with water. Some soils can experience a significant volume change upon a change of the degree of saturation. Soils that expand upon wetting are known as expansive soils, whilst soils that compress upon wetting are known as collapsible soils. Due to the very large volume changes that they may undergo, both of these soil types can severely damage foundations and the structures that they support. The shear strength of a soil can also change significantly as its degree of saturation changes, and a related engineering problem is slope failure caused by rainfall. Unsaturated soils also have distinct hydraulic properties which have significant implications in the performance of soil cover systems in waste containment.

Therefore, the key issues in unsaturated soil mechanics are (1) the volumetric behaviour associated with saturation or suction changes; (2) the strength behaviour associated with saturation

\footnotetext{
* Corresponding author. Fax: +612 49216991.

E-mail address: daichao.sheng@newcastle.edu.au (D. Sheng).
}

and suction changes, and (3) the hydraulic behaviour associated with saturation or suction changes. In terms of constitutive modelling, the key question is how these issues can be incorporated into a saturated soil model so that it can also be used for unsaturated states as well. In the first part of this paper alternative methods for addressing these key issues in unsaturated soil models are discussed. In particular, the focus is put on the comparison between a recent model that the authors are associated with and the other common models. As such, the coverage of the paper is inevitably selective, and can not serve as a complete state-of-the-art review of the subject of constitutive modelling of unsaturated soils. The second part of the paper outlines the challenges and solutions for implementing unsaturated soil models into the finite element method.

\section{Constitutive modelling: an overview}

\subsection{Stress and strain variables}

Constitutive relations used to represent the mechanical behaviour of materials are usually described in a stress space. The choice of the stress space is thus a fundamental issue in constitutive modelling. Ideally the definition of stresses should be independent of the behaviour or the states of the material, so that the stress space does not change with the material state. There is little argument that total stresses should be used for single phase materials such as metals and dry sands. It is also widely accepted by the soil mechanics community that effective stresses (the difference 
between the total stresses and pore water pressure) can be used for saturated soils. The definitions of the total stresses for dry soils and the effective stresses for saturated soils are naturally independent of the soil behaviour or soil state. The stress spaces in these cases are thus separated from the material state. We also note that the so-called total stress in a dry sand is actually the difference between the absolute total stress and the atmospheric pore air pressure.

For soils that are partially saturated with one pore fluid, the choice of the stress space becomes more complicated and the stress space may become dependent on the material state. In 1960s, great efforts were made to identify a single effective stress that can be used to describe the deformation and strength characteristics of unsaturated soils [1]. Bishop [8] suggested the following effective stress concept

$\sigma_{i j}^{\prime}=\sigma_{i j}-u_{\mathrm{a}} \delta_{i j}+\chi\left(u_{\mathrm{a}}-u_{\mathrm{w}}\right) \delta_{i j}=\bar{\sigma}_{i j}+\chi s \delta_{i j}$

where $\sigma_{i j}$ is the total stress, $\sigma_{i j}^{\prime}$ is the Bishop effective stress, $\bar{\sigma}_{i j}$ is the net stress, $u_{\mathrm{a}}$ is the pore air pressure, $u_{\mathrm{w}}$ is the pore water pressure, $s$ is the soil (matric) suction, and $\chi$ is a parameter that may depend on the degree of saturation or on the suction. The soil suction in this paper refers to the matric suction which consists of the capillary and adsorptive potentials. When the pore water exists as capillary water at relatively high degrees of saturation, the capillary potential $\left(\Psi_{\mathrm{c}}\right)$ is dominant in the matric suction $s \simeq \Psi_{\mathrm{c}}=u_{\mathrm{a}}-u_{\mathrm{w}}$. When the pore water exists as adsorbed water films in the soil, the adsorptive potential $\left(\Psi_{\text {a }}\right)$ becomes dominant in the matric suction. In this case
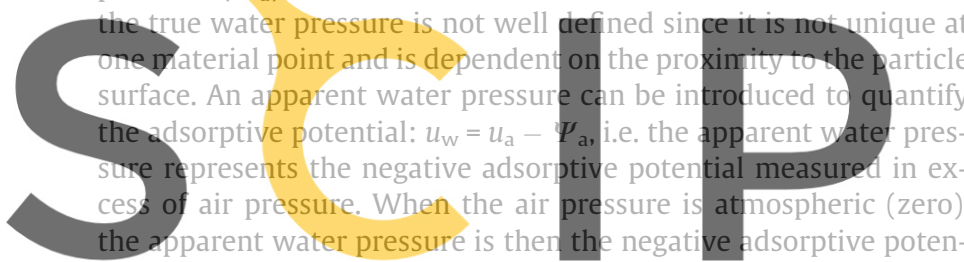

tial. Such an apparent water pressure is then unique at one materia point. With such a definition of $u_{w}$, the matric suction can be ex-

Registerefors free mahttps/k/waAdsanscipipedie.colanivo large range of saturation, from fully saturated to very dry states.

Even though the new definition of the effective stress in 1960s

has led to some success in describing the shear strength of unsaturated soils, it has not led to great success in modelling the general mechanical behaviour of unsaturated soils, not at least until the last decade or so. Some limitations of the single Bishop effective stress in explaining volume collapse during wetting of unsaturated soils were reported by Jennings and Burland [36]. More importantly, because the parameter $\chi$ usually depends material states (e.g. the degree of saturation) and even on stress path (e.g. the transition suction between saturated and unsaturated states), the stress space defined by Eq. (1) depends on the material behaviour and changes with material states. Therefore, the constitutive behaviour of the material is embodied in both the constitutive relation and the stress space where the constitutive relation is defined. As pointed out by Morgenstern [53], we normally link equilibrium considerations to deformations through constitutive behavior and should not introduce constitutive behavior into the stress state.

In 1960s and 1970s, it was realised that it was possible to use two independent sets of stress variables to model unsaturated soil behaviour rather than combining them into one single effective stress. For example, Coleman [14] suggested the use of the net axial and radial stresses and the net pore water pressure to represent triaxial stress states. Bishop and Blight [9] used the concepts of independent stress state variables when plotting volume changes in an unsaturated soil. [51] used the independent stress variables (called 'state parameters') to describe the volumetric behaviour of unsaturated soils. Numerous other researchers have subsequently pre- sented the volume change behaviour as surfaces defined by independent stress state variables $[2,18,5]$.

Fredlund and Morgenstern [19] further provided a theoretical basis and justification for the use of two independent stress state variables. The justification was based on the superposition of coincident equilibrium stress fields for each of the phases of a multiphase system, within the context of continuum mechanics. Three possible combinations of independent stress state variables were shown to be justifiable from the theoretical continuum mechanics analysis. However, it was the net stress and the matric suction combination that proved to be the easiest to apply in engineering practice:

$$
\left(\begin{array}{c}
\sigma_{i j}-u_{\mathrm{a}} \delta_{i j} \\
u_{\mathrm{a}}-u_{\mathrm{w}}
\end{array}\right)=\left(\begin{array}{c}
\bar{\sigma}_{i j} \\
s
\end{array}\right)
$$

The net normal stress primarily accounts for the external application and removal of total stress (e.g., by excavations, fills and applied loads). The matric suction primarily accounts for the impact of the climatic environment above the ground surface. Fredlund et al. [20] also presented a shear strength equation using the independent stress variables.

In the context of constitutive modelling, Alonso et al. [4] were the first to provide a complete elasto-plastic framework for modelling unsaturated soil behaviour. This model uses the net stress and suction as the stress variables and became known as the Barcelona Basic Model. A large number of other elasto-plastic models soon

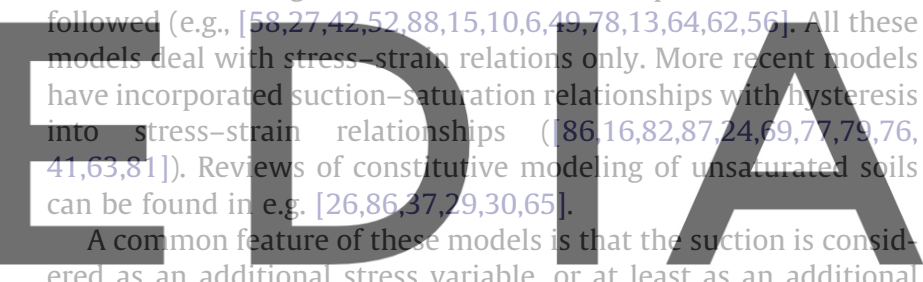
ered as an additional stress variable or atreastas an additional hardening parameter $[10,49]$. However, there is little consensus

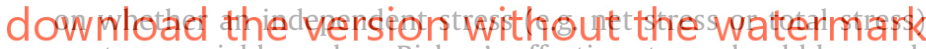
or stress variable such as Bishop's effective stress should be used. A different argument was put forth by Houlsby [34] using the work-conjugate variables in the work input for a soil element. In terms of work input, it is possible to define a set of strain variables that are work-conjugate to the chosen set of stress variables. For example, the work-conjugate strain variables for the two sets of independent stress variables, defined by the net stresses and the suction, are the soil skeleton strains and the volumetric water content:

$$
\left(\begin{array}{c}
\sigma_{i j}-u_{\mathrm{a}} \delta_{i j} \\
u_{\mathrm{a}}-u_{\mathrm{w}}
\end{array}\right) \Longleftrightarrow\left(\begin{array}{c}
\varepsilon_{i j} \\
\theta
\end{array}\right)
$$

where $\varepsilon_{i j}$ is the soil skeleton strain and $\theta$ is the volumetric water content. We note that the definitions of the stress variables in expression (3) are independent of each other and independent of material state. However, their work-conjugate strain variables are not independent, i.e. the soil skeleton strain and the volumetric water content are dependent on each other. It is also noted that the net stress becomes the total stress when the soil is fully saturated and the pore air is under atmospheric pressure. When the air pressure is kept at the atmospheric value (which is approximately true for most in situ conditions), the matric suction is equivalent to the negative pore water pressure. Early models using the net stress and suction thus suffer a major shortcoming in that they are not continuous at the transition between saturated states and unsaturated states, because the stress variables used for unsaturated states (total stress) do not change to the stress variables for saturated states (effective stress). However, it has recently been demonstrated in the SFG model by Sheng et al. [66] that this set 
of stress variables can also lead to a continuous description of soil behaviour. More discussion of the SFG model will be given in later sections.

On the other hand, the work-conjugate stress variables to the two sets of independent strain variables, defined by the soil skeleton strains $\left(\varepsilon_{i j}\right)$ and the degree of saturation $\left(S_{\mathrm{r}}\right)$, are the average stresses and a modified suction (ns). These strain variables are considered to be independent because a change in one of them does not necessarily result in a change in the other. The porosity $n$ plays a role in scaling the work input (due to a change in saturation) per unit void volume to the work input per unit volume of the soil matrix. Therefore, the second set of alternative stress variables takes the following form [69]:

$$
\left(\begin{array}{l}
\sigma_{i j}-u_{\mathrm{a}} \delta_{i j}+S_{r}\left(u_{\mathrm{a}}-u_{\mathrm{w}}\right) \delta_{i j} \\
\left(u_{\mathrm{a}}-u_{\mathrm{w}}\right)
\end{array}\right) \Longleftrightarrow\left(\begin{array}{c}
\varepsilon_{i j} \\
S_{r}
\end{array}\right)
$$

where $S_{r}$ is the degree of saturation. The stress variables defined in expression (4) are dependent on one another, as well as on the material state $\left(S_{\mathrm{r}}\right)$. The stress $\left(\sigma_{i j}-u_{\mathrm{a}} \delta_{i j}+S_{r}\left(u_{\mathrm{a}}-u_{\mathrm{w}}\right) \delta_{i j}\right)$ becomes the Terzaghi effective stress $\left(\sigma_{i j}-u_{\mathrm{w}} \delta_{i j}\right)$ when the soil becomes saturated. Therefore, the above stress variables can be used both for saturated and unsaturated states. The stress $\left(\sigma_{i j}-u_{\mathrm{a}} \delta_{i j}+\right.$ $\left.S_{\mathrm{r}}\left(u_{\mathrm{a}}-u_{\mathrm{w}}\right) \delta_{i j}\right)$ is also called Bishop's stress and has been found to represent the average stress acting on the solid phase by Hassanizadeh and Gray [32] using the entropy inequality exploited via the Colemann-Noll procedure, by Lewis and Schrefler [45] using
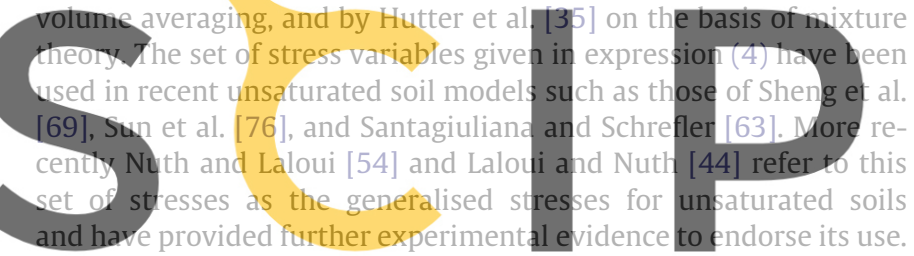

It should be noted that the stress or the strain variables in expressions (3) and (4) may not have the same physical meanings.

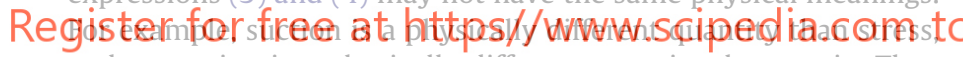
and saturation is a physically different quantity than strain. They are grouped together to form spaces for establishing constitutive relations. This is very similar to choosing a coordinators system (e.g. $x, y, z, t$ ) to describe a function. We also note that stress and suction have the same unit, which is why the two variables can sometimes be added together through dimensionless multiplies $\left(\chi, S_{\mathrm{r}}\right.$ or 1$)$. In this context, the argument that suction is physically not a stress variable [50] is not particularly pertinent.

It is also generally true that the complex stress variables defined by expression (4) tend to lead to simpler constitutive equations, whereas the simpler stress variables defined by expression (3) tend to lead to more complex constitutive equations. The complex stress variables in expression (4) depend on material states and are not easily controllable in laboratory testing. Therefore, it is not possible to develop a completely new constitutive relationship in terms of these variables, unless an existing framework is used. However, it is possible to transform an existing constitutive relationship formed in terms of the simpler stress variables (expression (3)) to the complex stress space. Such a transformation can often overcome the discontinuity problem at the transition between saturated and unsaturated states, as was done by Sheng et al. [70,72] for the Barcelona Basic Model, or more recently by Kohler and Hofstetter [43] for the cap model. In this regard, it is probably preferable to call the complex stress in expression (4) the constitutive stress rather than the effective stress, meaning that they are specific variables used for constitutive modelling $[69,29]$. However, we have kept the terminology 'Bishop's effective stress' in this paper for consistency with other publications in the area. The choice of the stress variables also has a significant influence on the yield and failure surfaces, which is later discussed in this paper.

\subsection{Constitutive models for unsaturated soils}

The first complete elasto-plastic models designed explicitly for unsaturated soils was presented in [4] (and in a more summary form in [28]. This model was formulated in terms of net stresses and suction. With some slight modifications, it came to be known as the Barcelona Basic Model (BBM) and can perhaps be summarised by Fig. 1, where a three dimensional yield surface in $\bar{p}-q-s$ space is depicted. Here, $\bar{p}$ is the mean net stress and $q$ is the deviator stress. Under saturated conditions, the yield surface corresponds to the Modified Cam Clay (MCC) ellipse [61] and the size of the elastic domain increases as the suction increases. The rate of increase, represented by the Loading-Collapse (LC) curve, is one of the fundamental characteristics of the model.

One of the main objectives of the development of the BBM was to try to insert unsaturated soil mechanics into the mainstream of current and past developments in saturated soil mechanics. This aim guided many of the choices adopted in the definition of the model and explains the rough simplicity of many of its features. It was intended that the model could be used to make qualitative predictions by simple hand manipulation in the same way that the conceptual critical state framework is often used. This implied the adoption of net stresses as one of the basic stress variables. If other stress variables are used, it is quite difficult to follow conven-

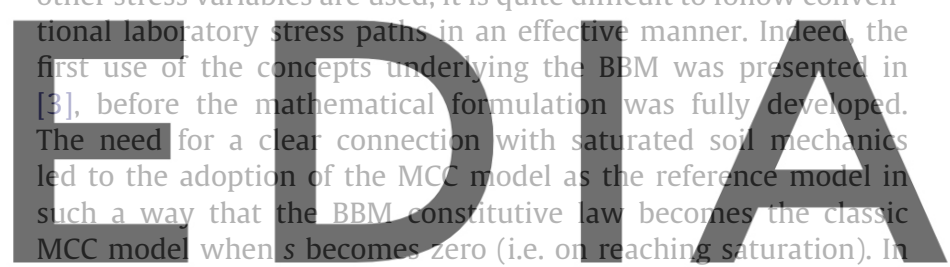

fact, many other elasto-plastic saturated models could have been used, as the unsaturated formulation is quite general (see, for

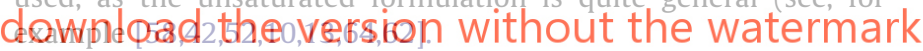

Further examples of the simplifying assumptions adopted in the model are the use of straight lines for the void ratio $-\ln p$ relationships (implying a continuous increase of the collapse strains upon wetting) and the linear increase of apparent cohesion with suction. A direct benefit of this simplicity is that only a limited number of additional parameters are required. Moreover, in spite of its lack of complexity, the model can describe a large number of typical features of the mechanical behaviour of unsaturated soils in a natural unforced way $[3,4]$. Some examples are: the variation of wetting-induced swelling or collapse strains depending on the magnitude of applied stresses, the reversal of volumetric strains observed sometimes during wetting-induced collapse, the increase

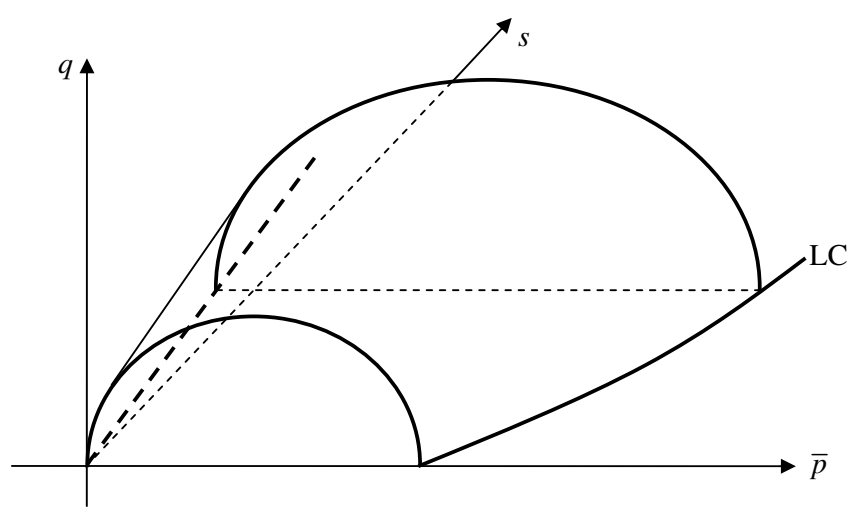

Fig. 1. Three dimensional yield surface of Barcelona basic model. 
of shear strength with suction, the stress path independency associated with wetting paths and the opposite when the stress path involves drying or the apparent increase of preconsolidation stress with suction.

Following the introduction of the BBM, other models were quickly developed that sought to limit some of its shortcomings, while at the same time keeping the same core of basic assumptions. Thus [38] used non linear relationships for the variation of void ratio with $\ln p$ so that the collapse strains did not increase indefinitely but went through a maximum before reducing to zero at high stresses. Gens and Alonso [27] and Sánchez et al. [64] extended the BBM for highly expansive soils by considering the interaction between macrostructures and microstructures and generalised plasticity theory. Wheeler and Sivakumar [88] used model functions more closely based on experimental results. Cui et al. (1995) adopted a saturated yield function typical of anisotropically consolidated soils. More recently, the mechanical parts of the hydromechanical models of Vaunat et al. [821, W/heeler et al. [87], Gallipoli et al. [24], Sheng et al. [69] and Sun et al. [76] all follow a framework similar to the BBM, with the effects of saturation being considered by incorporating soil-water characteristic curves and hydraulic hysteresis.

Instead of going through the different features of various models in detail, we will discuss how key issues can be incorporated into a saturated soil model so that it can also be used for unsaturated states as well. These key issues include (1) the volumetric behaviour associated with saturation or suction changes; (2) the

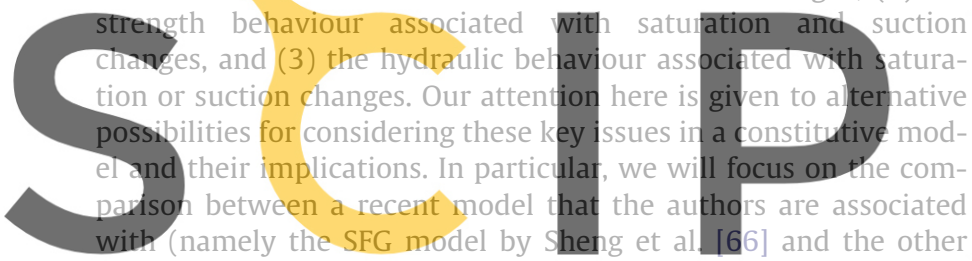
common models such as the BBMI)

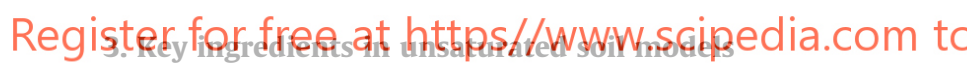

\subsection{Volumetric stress-strain models}

Suction affects the volumetric behaviour, yield stress and shear strength of an unsaturated soil. It generates capillary inter-particle forces normal to contacts, while pore pressures generate isotropic stresses around soil particles. As such, it plays a more complex role than the pressure or mean stress. As pointed out by Li [46], some measure of soil fabric should be incorporated when considering the effects of suction. However, any such measure is difficult to define and has not yet been used in constitutive modelling. Instead, suction is usually treated as a similar quantity to the mean stress. Under such a framework, the only extra constitutive law that is required to extend a saturated soil model to unsaturated soils is the volume-stress-suction relationship. The effects of suction on the yield stress and shear strength can be incorporated into the model based on the volume-stresssuction relationship.

The change in the specific volume $(v)$ of an unsaturated soil in response to suction $(s)$ or mean stress $(p)$ change is typically modelled in one of the following ways:

$$
\begin{aligned}
& \mathrm{d} v=\frac{\mathrm{d} N(s)}{\mathrm{d} s} \mathrm{~d} s-\lambda_{\mathrm{vp}}(s) \frac{\mathrm{d} \bar{p}}{\bar{p}}-\ln \bar{p} \frac{\mathrm{d} \lambda_{\mathrm{vp}}(s)}{\mathrm{d} s} \mathrm{~d} s \\
& \mathrm{~d} v=\frac{\mathrm{d} N(s)}{\mathrm{d} s} \mathrm{~d} s-\lambda_{\mathrm{vp}}(s) \frac{\mathrm{d} p^{\prime}}{p^{\prime}}-\ln p^{\prime} \frac{\mathrm{d} \lambda_{\mathrm{vp}}(s)}{\mathrm{d} s} \mathrm{~d} s \\
& \mathrm{~d} v=-\lambda_{\mathrm{vp}} \frac{\mathrm{d} \bar{p}}{\bar{p}}-\lambda_{\mathrm{vs}} \frac{\mathrm{d} s}{\mathrm{~s}}
\end{aligned}
$$

where $\lambda_{\mathrm{vp}}$ is a material parameter representing the stress compressibility under constant suction, $\bar{p}$ is the net mean stress, $p^{\prime}$ is Bishop's effective mean stress, $\lambda_{\mathrm{vs}}$ is a material parameter representing the suction compressibility under constant mean stress, and $N(s)$ is the specific volume of the soil when the mean stress is 1 (unit of stress). The parameters $N$ and $\lambda_{\mathrm{vp}}$ in Eqs. (5) and (6) and the parameter $\lambda_{\text {vs }}$ in Eq. (7) are usually considered as functions of suction. Over a certain stress range, the parameter $\lambda_{\mathrm{vp}}$ is usually approximated by one or two constants, depending on the preconsolidation pressure. Eqs. (5) and (6) are usually presented in the literature in total forms. All these equations imply linear relationships in the $v-\ln \bar{p}-\ln s$ space. It is also common to assume linear relationships in the $\ln v-\ln \bar{p}-\ln s$ space. In the later case, the differential of the specific volume $(\mathrm{d} v)$ can be replaced by the negative differential of the volumetric strain $\left(-\mathrm{d} \varepsilon_{v}\right)$.

Eq. (5) uses the net stress $\bar{p}$ and is used in the Barcelona Basic Model of Alonso et al. [4] and many other models. Eq. (6) uses Bishon's effective stress and is used in the formulations of Kohgo et al. [42], Bolzon et al. [10] and Loret and Khalili [49]. Eq. (7) uses the net stress $\bar{p}[21]$ and separates the compressibility due to a stress change $\left(\lambda_{\mathrm{vp}}\right)$ from that due to a suction change $\left(\lambda_{\mathrm{vs}}\right)$.

All these equations are of course based on Cam clay elasto-plasticity for saturated soils:

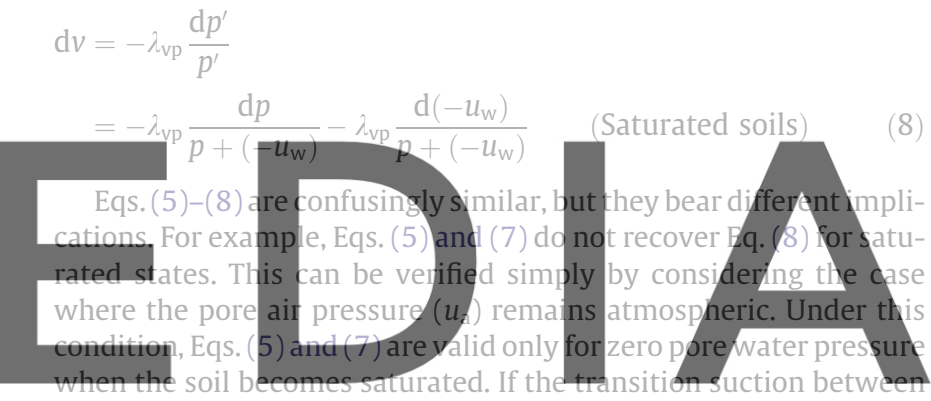

saturated and unsaturated states is not zero, the stress-induced vol down ghang is thefined at this suction in Eqs (5) and (7) The reasop tive stress and that the zero suction does not sufficiently represent all saturated states. Indeed, a confusing concept that is often cited in the literature is to treat zero suction as the equivalent to saturated states. This concept has two shortcomings. First, it does not consider the different suction levels that correspond to full saturation $\left(S_{\mathrm{r}}=1\right)$ during drying and wetting respectively. Second, it does not provide a continuous treatment between positive and negative pore water pressures. When the pore air pressure remains constantly atmospheric, a better alternative would be to treat the atmospheric air pressure as zero and the suction as a negative pore water pressure for all saturated states. In this case, the net stress simply becomes the total stress and the suction becomes the negative pore water pressure. Such an alternative will provide a continuous transition between saturated and unsaturated states.

Eq. (6) fully recovers the standard model for saturated soils, but contains Bishop's effective stress parameter $\chi$. This parameter often depends on the material as well as the material state, leading to the questionable outcome that the stress space where the material is modelled changes with the material behaviour and even the material state. Eq. (7) separates the compressibility due to a stress change $\left(\lambda_{\mathrm{vp}}\right)$ from that due to a suction change $\left(\lambda_{\mathrm{vs}}\right)$. As such, the parameter $\lambda_{\text {vp }}$ is not necessarily a function of the suction, which is an advantage over the other two equations.

A schematic view of the predictions according to Eqs. (5) and (6) is shown in Fig. 2. These two models both have difficulty in explaining the curvature of the normal compression lines at positive suctions for soils dried from slurry. Let us consider the case where a slurry soil is first dried to a specified suction and then isotropically compressed 


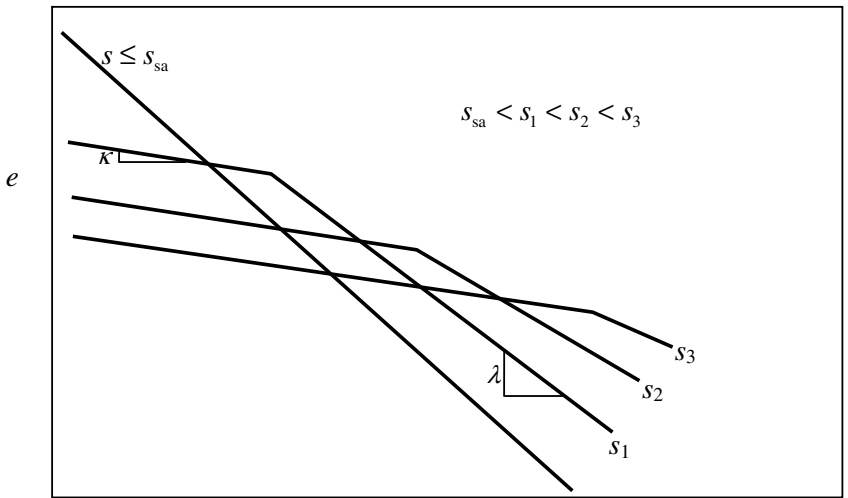

$\ln \bar{p}$ or $\ln p^{\prime}$

Fig. 2. Qualitative prediction of void ratio versus mean stress under constant suctions according to Equation (5), (6).

at this suction. The isotropic compression line for this soil is usually curved in the $e-\ln p$ space, as shown by Jennings and Burland [36]. To approximate this response using Eqs. (5) and (6), we would have to use the overconsolidation concept, so that the curve is approximated by two straight lines, an initial elastic line with a slope of $\kappa$ followed by an elasto-plastic line with a slope of $\lambda$, as illustrated in Fig. 2. However, the stress and the suction have never been decreased during the drying and loading processes and the slurry soil

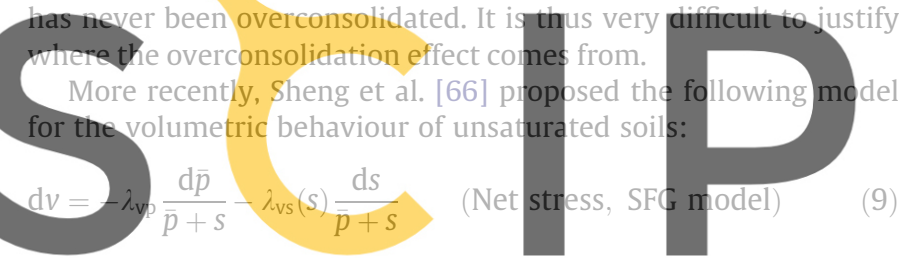

where the slope $\lambda_{\text {vp }}$ can be independent of suction, and the slope $\lambda_{v s}$

varies between $\lambda_{\text {vp }}$ for saturated states and zero for suctions above

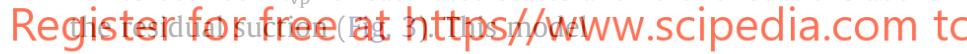

1. Recovers the equation for saturated states, i.e. Eq. (8).

2. Separates the compressibility due to stress and suction changes.

3. Can predict the smooth curvature of the normal compression lines under constant suctions for soils dried from slurry, without the use of the 'overconsolidation' concept (see Fig. 4).

Eq. (9) is very similar to Eq. (8), but with the negative pore water pressure replaced by the suction and the total mean stress

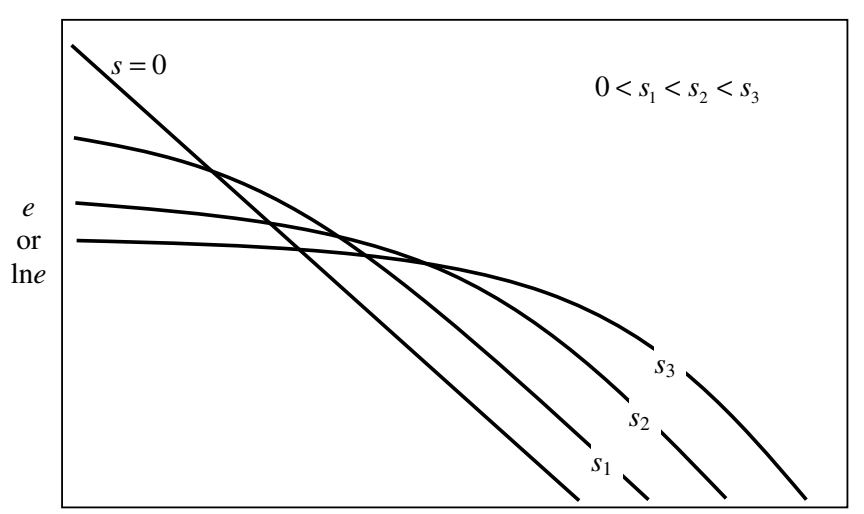

$\ln \bar{p}$

Fig. 4. Qualitative prediction of the normal compression curves under constant suctions according to Equation (9), (11).

replaced by the net mean stress. It is also reasonable to state that a change in suction does not necessarily have the same effect as a change in mean stress once the soil becomes unsaturated. Sheng et al. [66] showed that Eq. (9) can capture a number of important features in unsaturated soil behaviour and can represent experimental data very well.

Another issue with all the above volumetric models concerns the suction ranges and soil types where they can be applied. Firstly

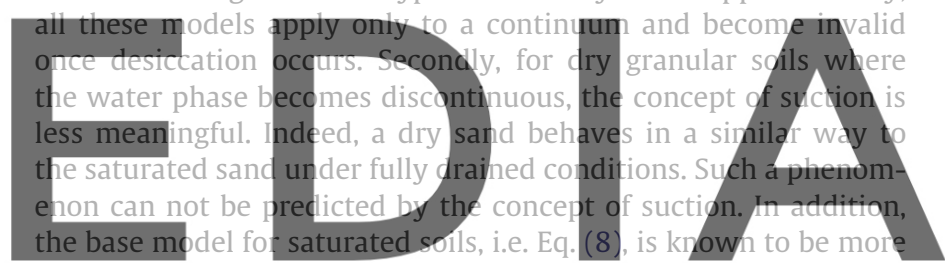

applicable to clays than to granular soils. Nevertheless, other constitutive models used for saturated soils can be generalised to

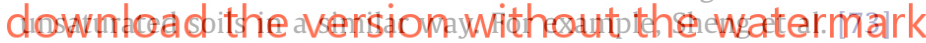
showed that the following equation predicts very well the volume change behaviour of saturated or dry sands:

$\frac{\mathrm{d} e}{e}=-\lambda_{\mathrm{vp}} \frac{\mathrm{d} p^{\prime}}{p^{\prime}+p_{\mathrm{re}}} \quad$ (Saturated sands)

where $e$ is the void ratio, and $p_{\text {re }}$ is a shifting stress which depends on the initial void ratio of the soil as well as $\lambda_{\mathrm{vp}}$, and it can be interpreted as the stress level where significant particle crushing occurs. Note that the parameter $\lambda_{\mathrm{vp}}$ in Eq. (10) is the slope in the double
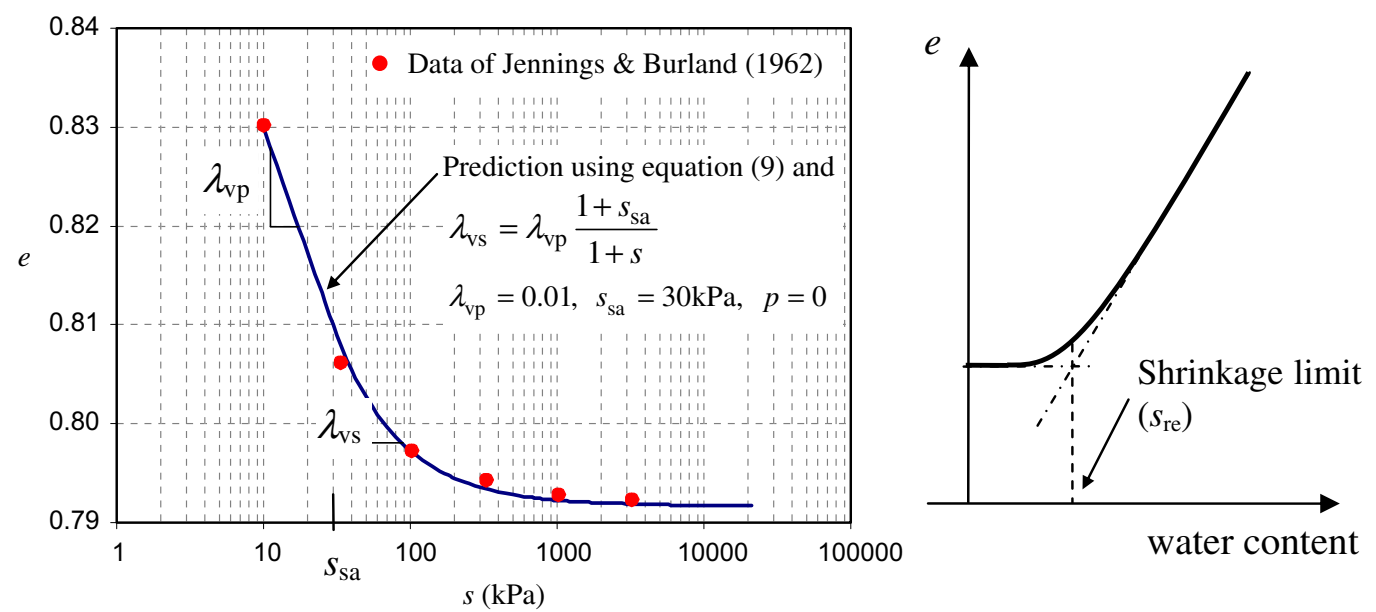

Fig. 3. Void ratio versus suction under zero net mean stress ( $s_{\mathrm{sa}}$ : suction corresponding to full saturation, $s_{\mathrm{re}}$ : residual suction, right: a classic shrinkage test result). 
logarithmic $\ln e-\ln \left(p^{\prime}+p_{\text {re }}\right)$ space. If Eq. (10) is used for a saturated sand, Eq. (9) can be modified as follows

$$
\frac{\mathrm{d} e}{e}= \begin{cases}-\lambda_{\mathrm{vp}} \frac{\mathrm{d} \bar{p}}{\bar{p}+p_{\mathrm{re}}+s}-\lambda_{\mathrm{vs}}(s) \frac{\mathrm{d} s}{\bar{p}+p_{\mathrm{re}}+s} & s \leqslant s_{\mathrm{re}} \\ -\lambda_{\mathrm{vp}} \frac{\mathrm{d} \bar{p}}{\bar{p}+p_{\mathrm{re}}+s_{\mathrm{re}}} & s>s_{\mathrm{re}}\end{cases}
$$

where $s_{\mathrm{re}}$ is the residual suction (see Fig. 3). A threshold suction $\left(s_{\mathrm{re}}\right)$ is introduced in Eq. (11) and above this value suction has no effect on the volume change. Because the residual suction for sands is relatively small $(<100 \mathrm{kPa})$ compared to pressure needed for particle crushing (1-100 MPa), the effect of suction on the volume change is relatively limited. Setting $p_{\mathrm{re}}=0$ in Eq. (10) recovers Eq. (8). Therefore, Eq. (11) can also be used for clays (with $p_{\mathrm{re}}=0$ ).

\subsection{Yield stress and yield surfaces}

Because suction is an additional stress variable, it is necessary to determine the variation of the yield stress with suction, or the extension of the yield surface in the stress-suction space. The yield surface for an isotropic hardening soil usually represents the contours of the plastic volumetric strain (i.e. the hardening parameter). As such, the variation of the yield stress with suction can be derived from the volumetric nodel. For example, for the volumetric model defined by Eq. (5), it is possible to show that the following function represents the contours of plastic volumetric strain in the $\bar{p}-s$ space (see [66]):
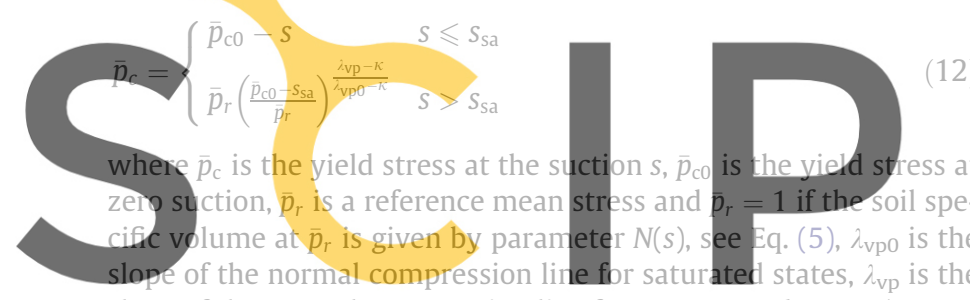
slope of the normal compression line for unsaturated states (at suction $s$ ), and $k$ is the slope of the unloading-reloading line for satu-

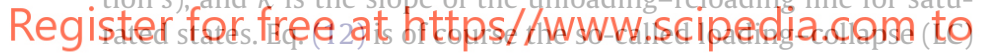
yield surface in the BBM of Alonso et al. [4], though only a part of the LC curve for $s>0$ (with $s_{\text {sa }}=0$ ) was defined in Alonso et al. [4].

A schematic view of the loading collapse yield surface defined by Eq. (12) is shown in Fig. 5a. A number of observations can be made here. Firstly, this yield surface is usually shown in the literature for suctions above the saturation suction only. Because the net stress becomes the total stress for saturated states, the yield surface actually follows the $45^{\circ}$ line for $s<s_{\text {sa }}$. Secondly, the yield stress $\bar{p}_{\mathrm{c}}$ increases with increasing suction only if (1) $\lambda_{\mathrm{vp}}<\lambda_{\mathrm{vp} 0}$ and $\bar{p}_{\mathrm{c} 0}>\bar{p}_{r}$, or (2) $\lambda_{\mathrm{vp}}>\lambda_{\mathrm{vp} 0}$ and $\bar{p}_{\mathrm{c} 0}>\bar{p}_{r}$. These two alternative conditions are a prerequisite to modelling wetting-induced collapse. Thirdly, an additional yield stress, $\bar{p}_{0}$, representing the

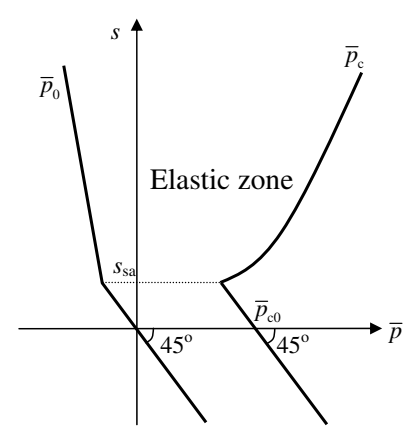

(a) net mean stress - suction space

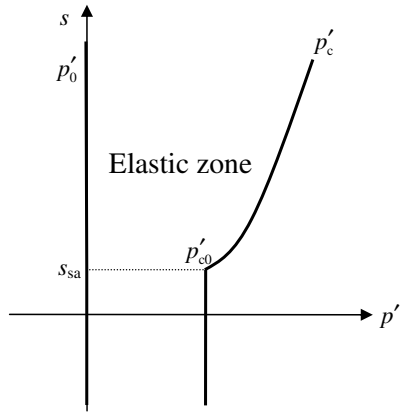

(b) effective mean stress - suction
Fig. 5. Schematic view of loading-collapse yield surface in mean stress-suction space. apparent tensile strength for $s>0$, has to be defined (see Fig. $5 a$ ). For the BBM, $\bar{p}_{0}$ takes the form:

$\bar{p}_{0}= \begin{cases}-s & s<s_{s a} \\ -\alpha s & s \geqslant s_{s a}\end{cases}$

On the other hand, if the volumetric model is based on Bishop's effective stress, i.e. Eq. (6), the corresponding yield stress becomes:

$p_{\mathrm{c}}^{\prime}= \begin{cases}p_{\mathrm{c} 0}^{\prime} & s \leqslant s_{\mathrm{sa}} \\ p_{r}^{\prime}\left(\frac{p_{\mathrm{c} 0}^{\prime}}{p_{r}^{\prime}}\right)^{\frac{\lambda_{\mathrm{vp}}-\kappa}{\operatorname{vvp} 0^{-\kappa}}} & s>s_{\mathrm{sa}}\end{cases}$

$p_{0}^{\prime}=0$

In Eq. (14), $p_{r}^{\prime}$ is a reference mean stress and $p_{r}^{\prime}=1$ if the soil specific volume at $p_{r}^{\prime}$ is given by parameter $N(s)$, see Eq. (6). The yield surface $p_{c}^{\prime}$ is shown schematically in Fig. 5b. Because of the use of Bishop's effective stress, it is usually assumed that an apparent cohesion is zero. In addition, the loading-collapse yield surface extends to the saturated zone following a vertical line. Since the effective mean stress is not constant under constant net mean stress but varying suction, there are certain constraints on the effective stress definition which have not been well discussed in the literature. For example, the effective mean stress must decrease slower than the yield stress as suction decreases under constant net mean stress, in order to model wetting-induced collapse. On the other hand, the effective mean stress must increase faster than the yield stress as suction increases under

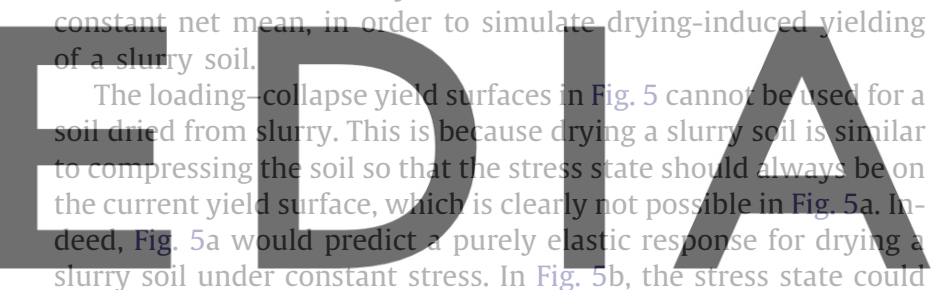
be on the current yield surface only if the effective mean stress in-

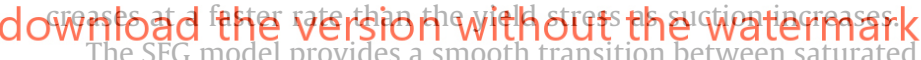
and unsaturated states. The yield stresses, $\bar{p}_{0}$ and $\bar{p}_{c}$, can be derived from the volumetric model, i.e. Eqs. (9) and (11), provided that the plastic volumetric strain is taken as the hardening parameter and that an explicit function for the parameter $\lambda_{\mathrm{vs}}$ is given. For example, the following yield stress was derived from Eq. (9) for a soil consolidated from a slurry state:

$\bar{p}_{\mathrm{c}}=\left\{\begin{array}{lr}\bar{p}_{\mathrm{c} 0}-s & s \leqslant s_{\mathrm{sa}} \\ \bar{p}_{\mathrm{c} 0}-s_{\mathrm{sa}}-\left(s_{\mathrm{sa}}+1\right) \ln \frac{s+1}{s_{\mathrm{sa}}+1} s>s_{\mathrm{sa}}\end{array}\right.$

This yield stress decreases with increasing suction. Therefore, drying a slurry soil will always cause the stress point on the current yield surface (see Fig. 6). For a slurry soil that has never been consolidated, $\bar{p}_{\mathrm{c} 0}$ is zero. The yield stress then becomes

$\bar{p}_{0}= \begin{cases}-s & s<s_{\mathrm{sa}} \\ -s_{\mathrm{sa}}-\left(s_{\mathrm{sa}}+1\right) \ln \frac{s+1}{s_{\mathrm{sa}}+1} \quad s \geqslant s_{\mathrm{sa}}\end{cases}$

The above yield stress $\bar{p}_{0}$ also defines the apparent tensile strength of the soil as a function of suction. For an unsaturated soil that is compressed or compacted at a suction above the saturation suction, the yield stress $\bar{p}_{\mathrm{c}}$ then changes to [66]:

$\bar{p}_{\mathrm{cn}}= \begin{cases}\bar{p}_{\mathrm{cn} 0}-s & s<s_{\mathrm{sa}} \\ \frac{\bar{p}_{\mathrm{cn} 0}}{\bar{p}_{\mathrm{c} 0}}\left(\bar{p}_{\mathrm{c} 0}+s-s_{\mathrm{sa}}-\left(s_{\mathrm{sa}}+1\right) \ln \frac{s+1}{s_{\mathrm{sa}}+1}\right)-s & s \geqslant s_{\mathrm{sa}}\end{cases}$

where $\bar{p}_{\mathrm{c} 0}$ is the initial preconsolidation pressure at zero suction, $\bar{p}_{\text {cno }}$ is the new preconsolidation pressure at zero suction (see Fig. 6). 


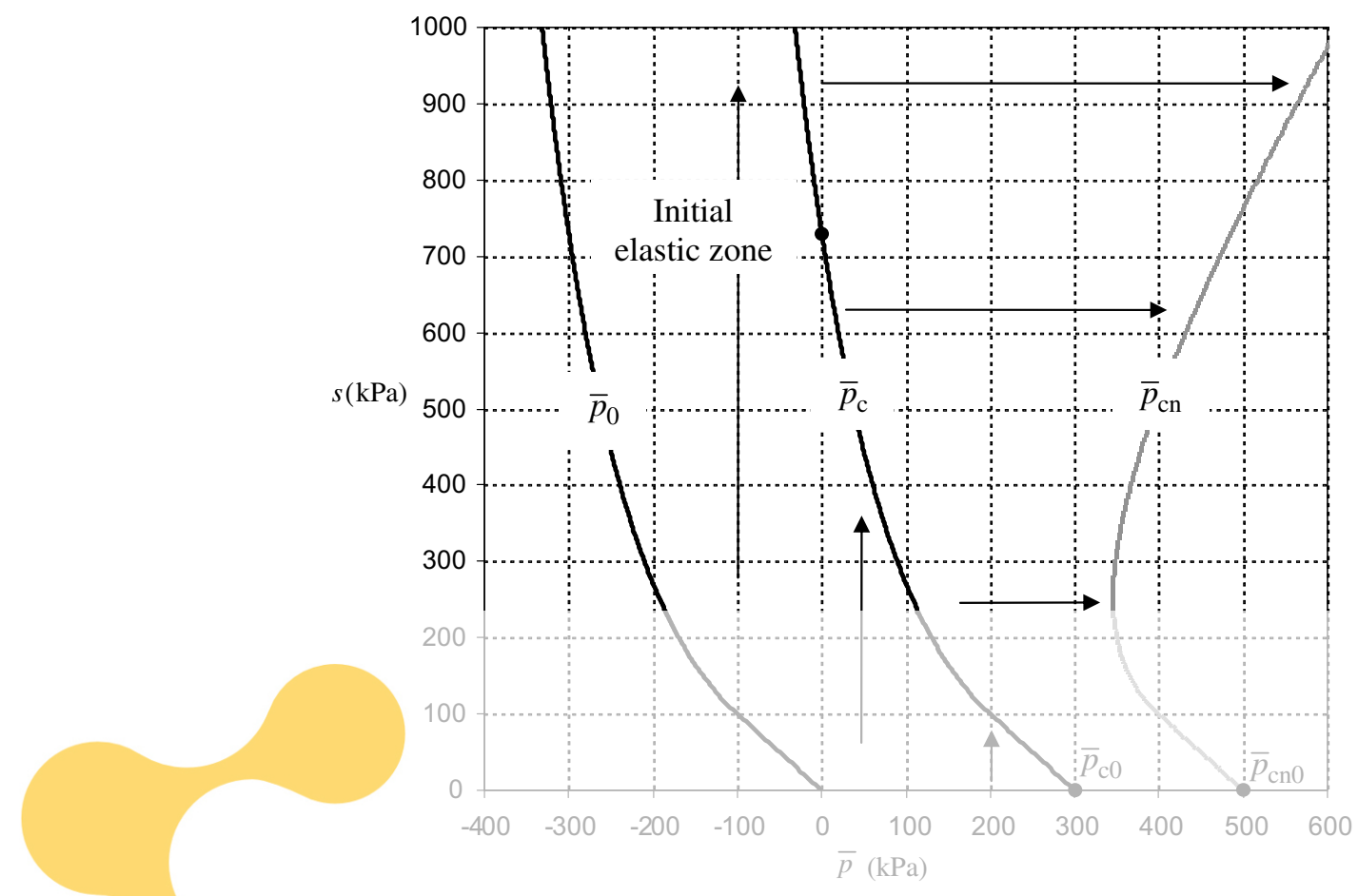

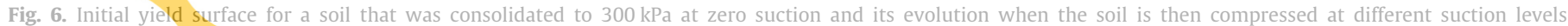

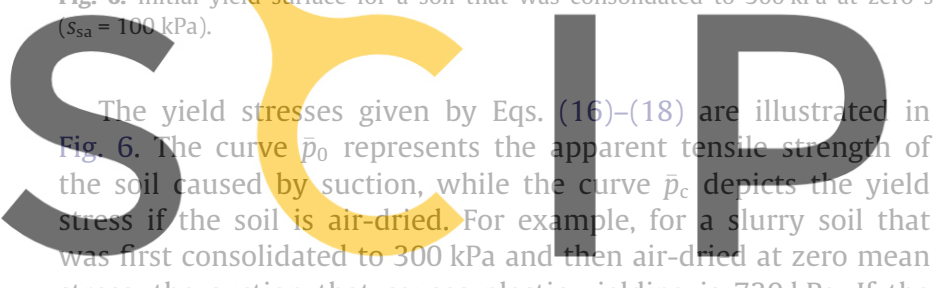

stress, the suction that causes plastic yielding is $730 \mathrm{kPa}$. If the

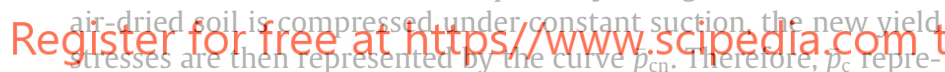

sents the yield stress for an air-dried slurry soil and $\bar{p}_{\mathrm{cn}}$ represents

the yield stress for a compacted soil. The yield stress increases with increasing suction along the curve $\bar{p}_{\mathrm{cn}}$, not $\bar{p}_{\mathrm{c}}$. It can also be noted that (1) the transition between saturated and unsaturated states is continuous and smooth along all the three yield stresses; (2) like the models in Fig. 5, the yield surfaces $\bar{p}_{\mathrm{c}}$ and $\bar{p}_{\mathrm{cn}}$ are non-convex in the $\bar{p}-s$ space; (3) the model is stress-path dependent and different stress paths may result in different yield surfaces.

If the Modified Cam Clay (MCC) model is used as the base model for the saturated soil, the elliptic yield surface can be extended to the suction axis according to Eqs. (16)-(18):

$f=q^{2}-M^{2}\left(\bar{p}-\bar{p}_{0}\right)\left(\bar{p}_{\mathrm{c}}-\bar{p}\right)=0$

where $f$ is the yield function, $q$ is the deviator stress, and $M$ is the shear strength parameter that defines the slope of the critical state line in $q-p$ space. The yield surfaces according to Eq. (19) are shown in Fig. 7 for two types of unsaturated soils.

\subsection{Shear strength with suction}

The shear strength of an unsaturated soil is usually a function of suction. Fredlund et al. [20] proposed the following relationship which conveniently separates the shear strength due to stress from that due to suction:

$$
\begin{aligned}
\tau & =\left[c^{\prime}+\left(\sigma_{\mathrm{n}}-u_{\mathrm{a}}\right) \tan \phi^{\prime}\right]+\left[\left(u_{\mathrm{a}}-\mathrm{u}_{\mathrm{w}}\right) \tan \phi^{b}\right] \\
& =\bar{c}+\left(\sigma_{\mathrm{n}}-u_{\mathrm{a}}\right) \tan \phi^{\prime}
\end{aligned}
$$
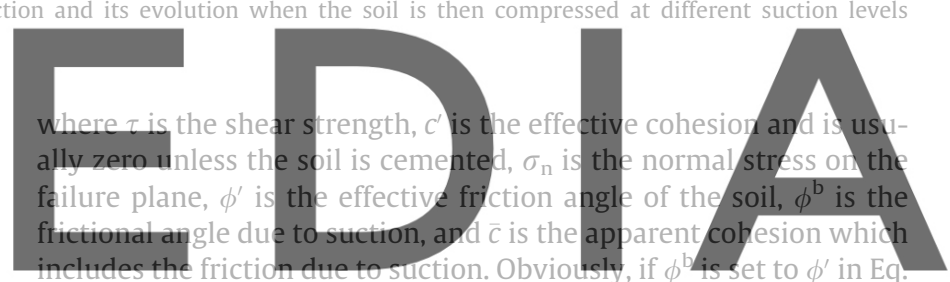

(20), the effective stress principle for saturated soils is recovered. down Thear stingth equation was oringilly published in a linear nonlinear (see, for example, [17]. The shear strength due to suction starts to deviate from the effective angle of internal friction at a suction which is approximately equal to the air entry value of the soil. The soil suction versus shear strength relationship then appears to have a gradual curvature until residual suction conditions are reached. Once these conditions are reached the shear strength remains approximately constant as the suctions are further increased. However, it is also possible for the shear strength to decrease for sands and increase for clays as the suctions are increased beyond residual conditions.

There are a number of models available in the literature for determining the friction angle $\phi^{\mathrm{b}}[84,23,55,7]$. In elasto-plastic models, the shear strength of an unsaturated soil is usually embodied in the apparent tensile strength function $\bar{p}_{0}$. For example, the apparent cohesion in the Barcelona Basic Model is given as

$\bar{c}=-\bar{p}_{0} \tan \phi^{\prime}=\left\{\begin{array}{l}s \tan \phi^{\prime} \quad s<s_{\mathrm{sa}}, C^{\prime}=0 \\ \alpha s \tan \phi^{\prime} s \geqslant s_{\mathrm{sa}}, c^{\prime}=0\end{array}\right.$

where $\alpha$ is a material constant. The friction angle $\phi^{\mathrm{b}}$ is then given by

$\tan \phi^{b}=\frac{\bar{c}}{s}=\left\{\begin{array}{l}\tan \phi^{\prime} \quad s<s_{\mathrm{sa}} \\ \alpha \tan \phi^{\prime} s \geqslant s_{\mathrm{sa}}\end{array}\right.$

In this case, the friction angle $\phi^{\mathrm{b}}$ is independent of suction.

In the SFG model, the apparent cohesion due to suction is

$$
\bar{c}=-\bar{p}_{0} \tan \phi^{\prime}= \begin{cases}s \tan \phi^{\prime} & s<s_{\mathrm{sa}}, c^{\prime}=0 \\ \tan \phi^{\prime}\left(s_{\mathrm{sa}}+\left(s_{\mathrm{sa}}+1\right) \ln \frac{s+1}{s_{\mathrm{sa}}+1}\right) & s \geqslant s_{\mathrm{sa}}, c^{\prime}=0\end{cases}
$$




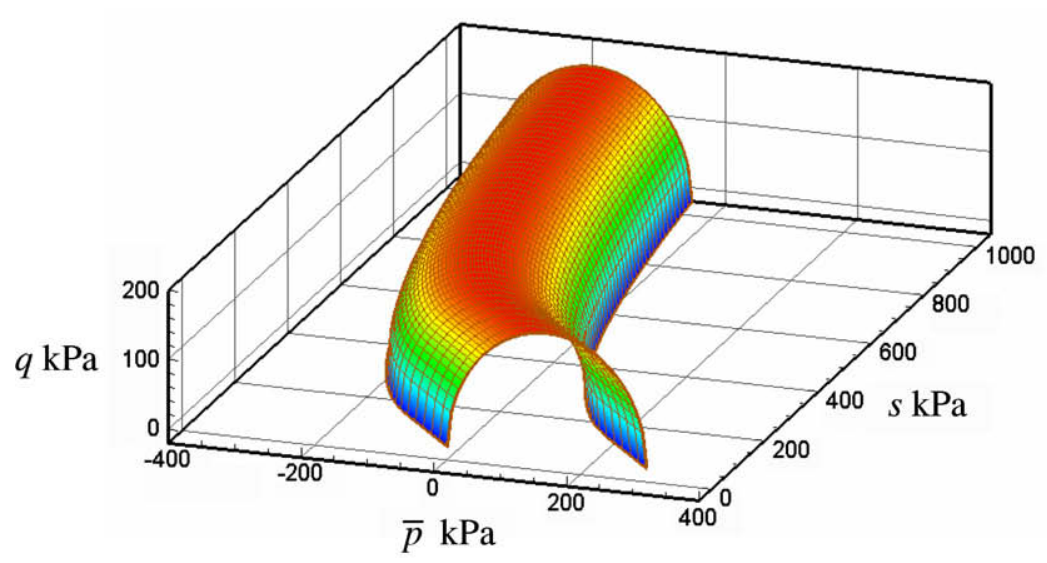

(a) Yield surface for air-dried soil from slurry.

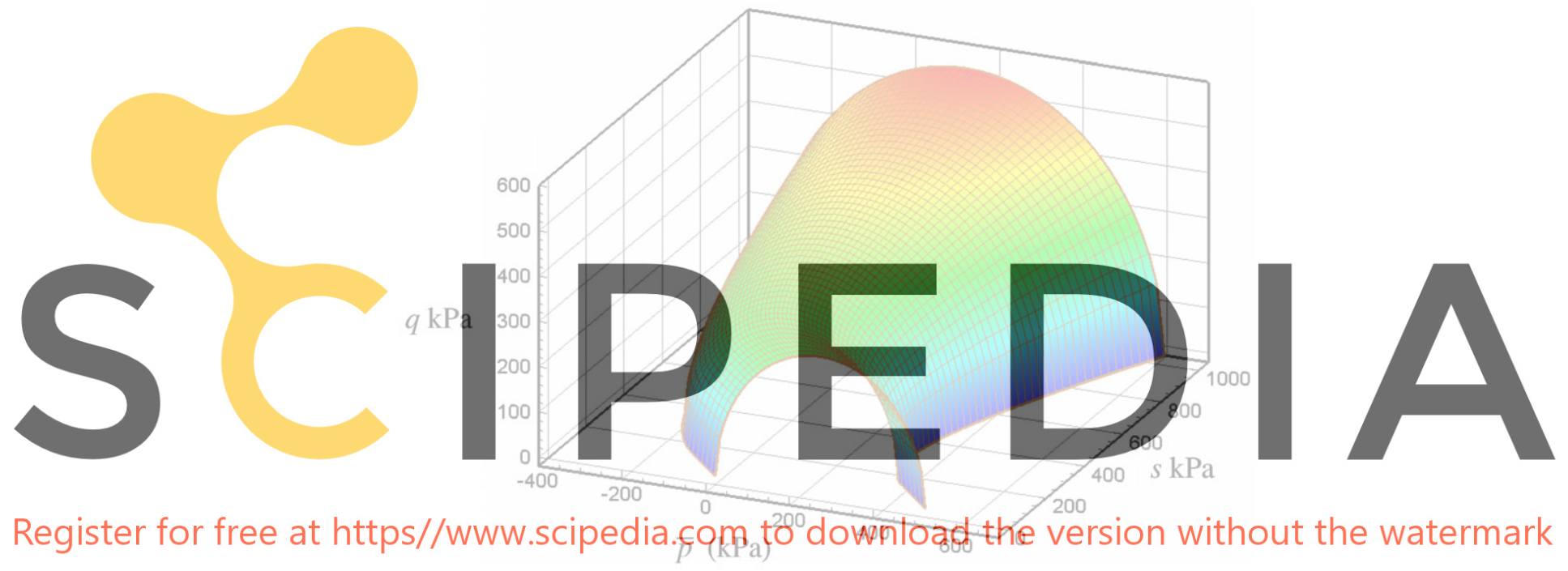

(b) Yield surface for compacted soil.

Fig. 7. Modified Cam Clay yield surfaces extended to suction axis $\left(s_{\mathrm{sa}}=100 \mathrm{kPa}\right)$.

Therefore, the friction angle $\phi^{\mathrm{b}}$ is given by:

$\tan \phi^{b}= \begin{cases}\tan \phi^{\prime} & s<s_{\mathrm{sa}} \\ \tan \phi^{\prime}\left(\frac{s_{\mathrm{sa}}}{s}+\frac{s_{\mathrm{sa}}+1}{s} \ln \frac{s+1}{s_{\mathrm{sa}}+1}\right) & s \geqslant s_{\mathrm{sa}}\end{cases}$

In this case, the friction angle $\phi^{\mathrm{b}}$ is a function of suction as well as the saturation suction. The predicted shear strength variation with suction is shown in Fig. 8 and compared with experimental data for Guadalix Red silty Clay in Fig. 9. The prediction of Eq. (24) appears to be reasonable, at least qualitatively.

On the other hand, if Bishop's effective stress is used, the shear strength is usually assumed to be unique in the effective stress space:

$\tau=c^{\prime}+\sigma_{\mathrm{n}}^{\prime} \tan \phi^{\prime}=c^{\prime}+\left(\sigma_{\mathrm{n}}-\mathrm{u}_{\mathrm{a}}\right) \tan \phi^{\prime}=\chi\left(\mathrm{u}_{\mathrm{a}}-\mathrm{u}_{\mathrm{w}}\right) \tan \phi^{\prime}$

The above equation also implies that $\tan \phi^{\mathrm{b}}=\chi \tan \phi^{\prime}$. Recently Nuth and Laloui [54] provided some experimental evidence for the uniqueness of $c^{\prime}$ and $\phi^{\prime}$ in Bishop's effective stress space with $\chi=S_{\mathrm{r}}$.

\subsection{Hysteresis of soil-water characteristics}

Extensive research has been done on soil-water characteristic curves for unsaturated soils, first in the field of soil physics and later within geotechnical engineering (see, e.g., [33]). The soil-water

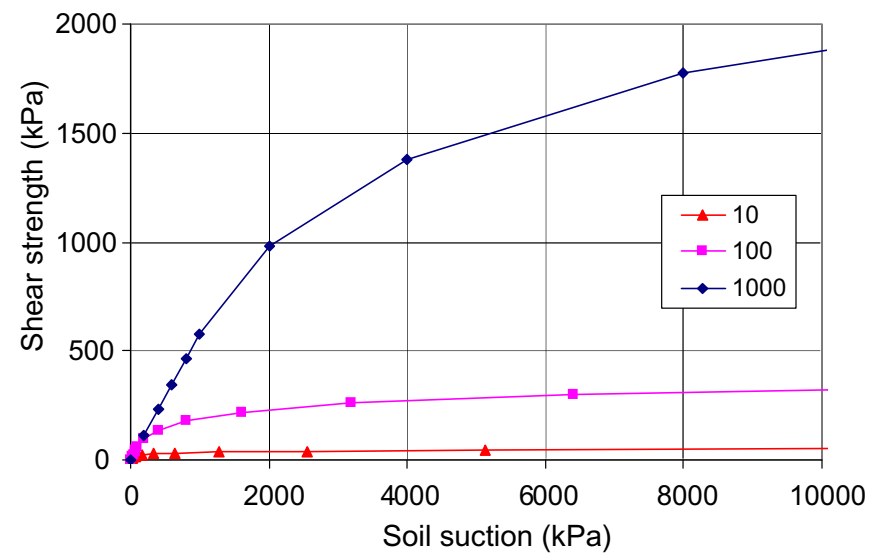

Fig. 8. Shear strength versus soil suction up to $10,000 \mathrm{kPa}$ for soils with air entry values of 10,100 , and $1000 \mathrm{kPa}$, predicted from equation (24).

characteristic curve (SWCC) is usually presented in the space of the volumetric water content $(\theta)$ versus soil suction or in the space of the degree of saturation $\left(S_{\mathrm{r}}\right)$ versus suction. A number of empirical $\theta-s$ relations exist in the literature, and the ones that are com- 


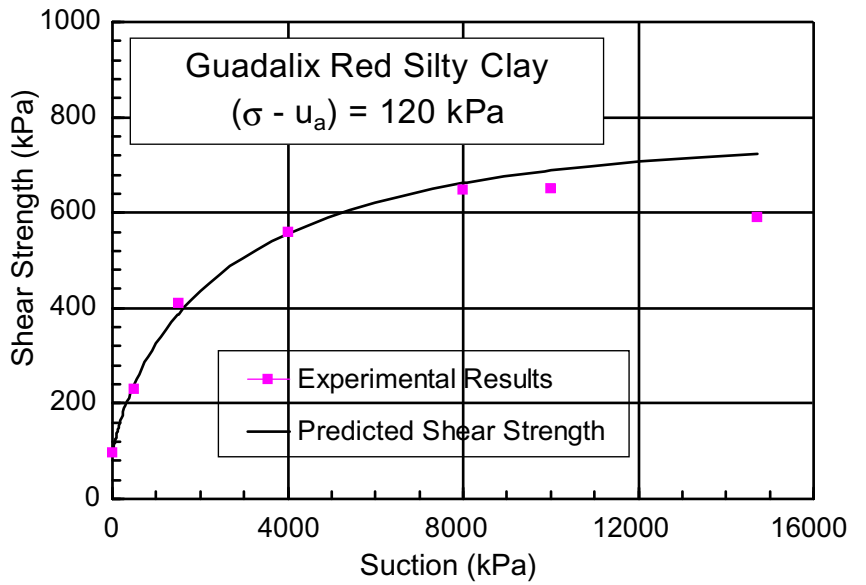

Fig. 9. Predicted shear strength values for Guadalix Red silty Clay [17] by equation (24).

monly used include those of Gardner [31], van Guenuchten [85] and Fredland and Xing [22]. These relations are usually written as continuous functions and do not explicitly consider the hysteretic behaviour during a drying-wetting loop. However, in an elasto-plastic modelling framework which must predict the responses for all possible wetting and drying paths, an incremental form (between $\mathrm{d} s$ and $\mathrm{d} \theta$ or between $\mathrm{d} s$ and $\mathrm{d} S_{\mathrm{I}}$ ) is preferred. Recently Li [47] presented an incremental soil-water characteristic relationShip between ds and $\mathrm{dS}_{\mathrm{r}}$. This incremental SWCC model includes smooth hysteretic responses to arb and can pe incorporated into elasto-p soils. However, the model by Li [47] fo $\mathrm{k}$ which is somewhat different from the classical elastoframework discussed in this paper. Lins et al. [48] presented a model for hysteretic SWCC from which an incremental Regarm, can also be established. More recently, Pedroso et al mulated in the same framework as elasto-plasticity and can be conveniently incorporated into an elasto-plastic stress-strain relation. In this paper, a very simple model presented by Sheng et al. [66] is described. This simple model does not consider the hysteretic behaviour within the main drying and main wetting curves (see Fig. 10).

As a simple approximation, a piece-wise linear relationship between the degree of saturation $S_{\mathrm{r}}$ and logarithmic soil suction can be assumed:

$\mathrm{d} S_{\mathrm{r}}=-\lambda_{\mathrm{ws}} \frac{\mathrm{d} s}{\mathrm{~s}}$

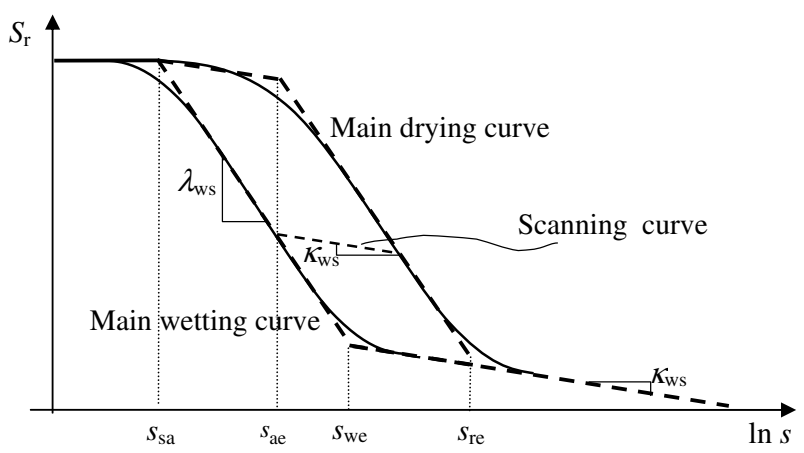

Fig. 10. Degree of saturation versus suction (dashed lines represent simplification). where the slope $\lambda_{\text {ws }}$ may change with suction. For soil suctions below the saturation suction, the soil is saturated and the degree of saturation remains essentially constant. For soil suctions larger than the residual suction, the water content gradually decreases to zero at a suction of $10^{6} \mathrm{kPa}[21]$. The slope is assumed to be constant between the air entry and the residual suction for a drying soil [87]. Therefore, we have, for increasing suction as shown in Fig. 10:

$\lambda_{\mathrm{ws}}=\left\{\begin{array}{l}0 \quad s<s_{\mathrm{sa}} \\ \kappa_{\mathrm{ws}} s_{\mathrm{sa}} \leq s<s_{\mathrm{sa}} \\ \lambda_{\mathrm{ws}} S_{\mathrm{ae}} \leq s<s_{\mathrm{re}} \\ \kappa_{\mathrm{ws}} s \geqslant s_{\mathrm{re}}\end{array}\right.$

where $s_{\mathrm{ae}}$ is the air entry value, and $s_{\mathrm{re}}$ is the residual suction (see Fig. 11). The above equation is only valid for the main drying curve. For the main wetting curve and the scanning curve, the slope must be adjusted accordingly (see Fig. 10). The soil suction versus water content relationship is affected by the mean net stress primarily through its influence on the air entry suction and the rate of desaturation (see, e.g., [83]), and is not considered here.

Hysteresis in soil-water characteristics is usually considered to be too important to ignore. Therefore, a wetting curve must be added to the drying curve. The wetting curve is characterised by the water entry value $s_{\text {we }}$ and has a similar slope to the drying curve, $\lambda_{\text {ws }}$ (see Fig. 10). A series of parallel lines having a slope $\kappa_{\text {ws }}$, are used to represent recoverable changes in $S_{\mathrm{r}}$ between the drying (desorption) and the wetting (adsorption) curves. These curves are called "scanning curves". For the purpose of this
study, the slope of the scanning curve is assumed to be identical
to the slope of the drying curve for suctions below the ait en try
value and for suctions above the residual value. The slope of
the wetting curve for suctions above the water entry value is also
assumed to be $\kappa_{\text {ws }}$ (see Fig. 10). The simplifications adopted here
are similar to those in the molel by Wheeler et/al. [87]. In the
simplified model, the maximum suction that colresponds to full saturation is the saturation suction $\left(s_{\mathrm{sa}}\right)$, not the air entry value d'ownload the version without the watermark
Hysteresis of soil-water characteristics can also be explained within the same framework of elasto-plasticity [69]. Under such a framework, an unsaturated state always lies within the main drying and wetting curves. Drying or wetting from within the hysteresis loops will only cause recoverable water content changes until the suction reaches the main drying or wetting curve. Once the soil suction reaches the main drying or wetting curve, further drying or wetting will cause irrecoverable water content changes. Therefore, the drying and wetting curves define the boundaries of recoverable water content change and are similar to the normal compression line. The scanning curves define the recoverable water content change and are similar to the unloading-reloading line. On the $\bar{p}-s$ plane, two additional boundaries can be added, representing the main drying and wetting curves, respectively (Fig. 11).

\section{Finite element implementation}

\subsection{Incremental stress-strain relations}

One of the ultimate goals of constitutive modeling is to develop an incremental stress-strain relation so that it can be implemented in a numerical method to solve boundary value problems. For unsaturated soils, these incremental relations can either be written as in [66]

$$
\left(\begin{array}{c}
\mathrm{d} \overline{\boldsymbol{\sigma}} \\
\mathrm{d} s
\end{array}\right)=\left(\begin{array}{cc}
\mathbf{D}^{\mathrm{ep}} & \mathbf{W}^{\mathrm{ep}} \\
\mathbf{R} & G
\end{array}\right)\left(\begin{array}{l}
\mathrm{d} \varepsilon \\
\mathrm{d} \theta
\end{array}\right)
$$

or as in [69] 


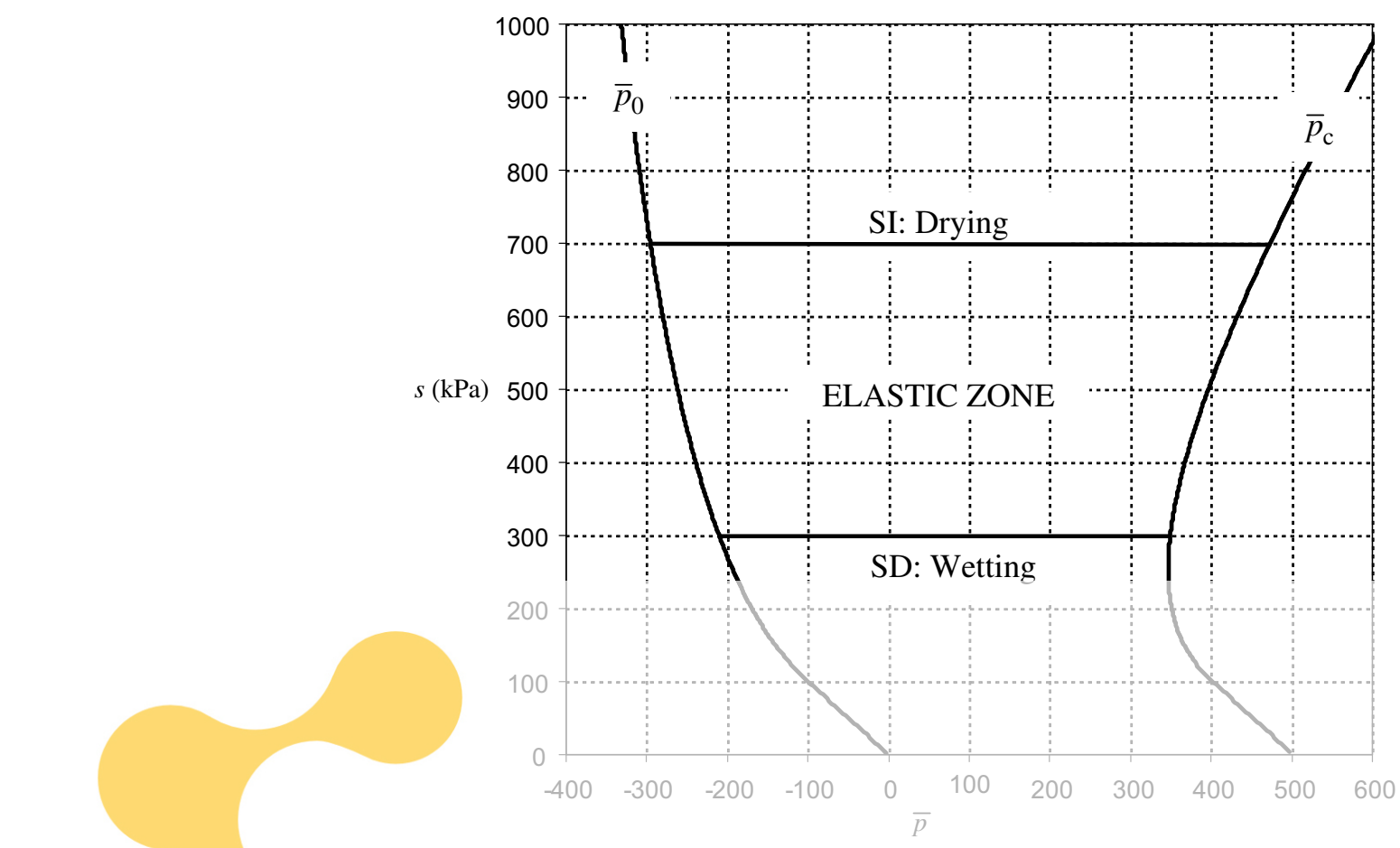

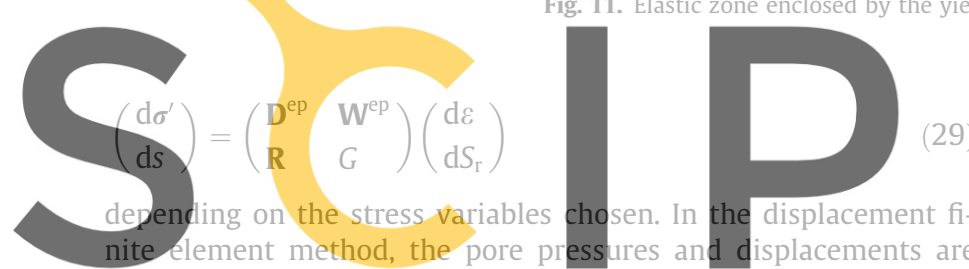
first solved from the equilibrium and continuity equations. There fore, the strain and suction increments are known, and the stress

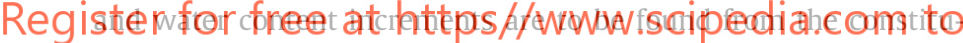
tive equations. In such a context, Eqs. (28) and (29) have to be reformulated so that all known increments are kept on the right-hand side.

Here the SFG model is used to demonstrate the derivation of the incremental stress-strain equation. The Modified Cam Clay model is used as the base model for saturated soils. The yield function then takes the form of

$F=q^{2}-M^{2}\left(\bar{p}-\bar{p}_{0}\right)\left(\bar{p}_{\mathrm{c}}-\bar{p}\right)=0$

The consistency condition becomes:

$\mathrm{d} f=\left(\frac{\partial f}{\partial \bar{\sigma}}\right)^{\mathrm{T}} \mathrm{d} \overline{\boldsymbol{\sigma}}+\frac{\partial f}{\partial \bar{p}_{0}} \frac{\partial \bar{p}_{0}}{\partial s} \mathrm{~d} s+\frac{\partial f}{\partial \bar{p}_{\mathrm{c}}} \frac{\partial \bar{p}_{\mathrm{c}}}{\partial s} \mathrm{~d} s+\frac{\partial f}{\partial \bar{p}_{\mathrm{c}}} \frac{\partial \bar{p}_{\mathrm{c}}}{\partial \varepsilon_{\mathrm{v}}^{p}} \mathrm{~d} \varepsilon_{\mathrm{v}}^{\mathrm{p}}=0$

The strain decomposition and the flow rule can be written as

$\mathrm{d} \boldsymbol{\varepsilon}=\mathrm{d} \boldsymbol{\varepsilon}^{\mathrm{e}}+\mathrm{d} \boldsymbol{\varepsilon}^{\mathrm{p}}=\mathrm{d} \boldsymbol{\varepsilon}^{\mathrm{e}}+\dot{\Lambda} \frac{\partial g}{\partial \overline{\boldsymbol{\sigma}}}$

where $g$ is the plastic potential function, and $\dot{A}$ is the plastic multiplier to be solved from the consistency condition.

The elastic stress-suction-strain relation can be written as

$\mathrm{d} \boldsymbol{\varepsilon}^{\mathrm{e}}=\left(\mathbf{D}^{e}\right)^{-1} \mathrm{~d} \overline{\boldsymbol{\sigma}}+\left(\underline{\mathbf{W}}^{\mathrm{e}}\right)^{-1} \mathrm{~d} s, \quad$ or

$\mathrm{d} \overline{\boldsymbol{\sigma}}=\mathbf{D}^{\mathrm{e}} \mathrm{d} \boldsymbol{\varepsilon}^{\mathrm{e}}-\mathbf{D}^{\mathrm{e}}\left(\underline{\mathbf{W}}^{\mathrm{e}}\right)^{-1} \mathrm{~d} s=\mathbf{D}^{\mathrm{e}}\left(\mathrm{d} \boldsymbol{\varepsilon}-\dot{\Lambda} \frac{\partial g}{\partial \boldsymbol{\sigma}}\right)-\mathbf{W}^{\mathrm{e}} \mathrm{d} s$

where $\mathbf{D}^{\mathrm{e}}$ is the elastic stress-strain stiffness matrix, $\underline{\mathbf{W}}^{\mathrm{e}}$ is the elastic suction-strain vector, and $\mathbf{W}^{\mathrm{e}}=\mathbf{D}^{\mathrm{e}}\left(\underline{\mathbf{W}}^{\mathrm{e}}\right)^{-1}$.

The plastic multiplier can be found from Eq. (31):

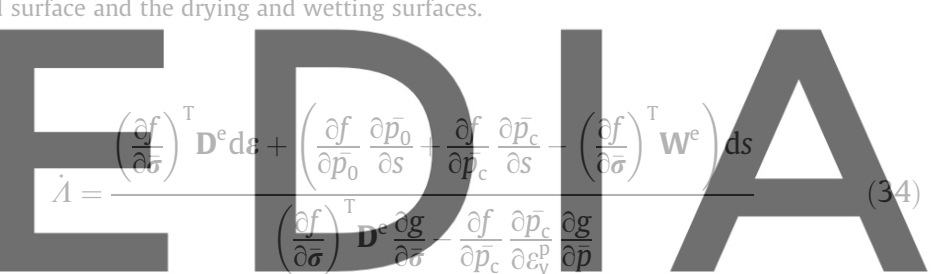

And the stress-strain relation is thus:

dowwnposed the version without the watermark

$$
-\frac{\mathbb{D}^{\mathrm{e}} \frac{\partial g}{\partial \bar{\sigma}}\left(\frac{\partial f}{\partial \bar{\sigma}}\right)^{\mathrm{T}} \mathbf{D}^{\mathrm{e}} \mathrm{d} \varepsilon+\mathbb{D}^{\mathrm{e}} \frac{\partial g}{\partial \bar{\sigma}}\left(\frac{\partial f}{\partial \bar{p}_{0}} \frac{\partial \bar{p}_{0}}{\partial s}+\frac{\partial f}{\partial \bar{p}_{\mathrm{c}}} \frac{\partial \bar{p}_{\mathrm{c}}}{\partial s}-\left(\frac{\partial f}{\partial \bar{\sigma}}\right)^{\mathrm{T}} \mathbf{W}^{\mathrm{e}}\right) \mathrm{d} s}{\left(\frac{\partial f}{\partial \overline{\boldsymbol{\sigma}}}\right)^{\mathrm{T}} \mathbf{D}^{\mathrm{e}} \frac{\partial g}{\partial \overline{\boldsymbol{\sigma}}}-\frac{\partial f}{\partial \bar{p}_{\mathrm{c}}} \frac{\partial \overline{p_{\mathrm{c}}}}{\partial \bar{\varepsilon}_{\mathrm{v}}} \frac{\partial g}{\partial \bar{p}}}
$$

The suction-water content relation is given by

$\mathrm{d} \theta=-n \lambda_{\mathrm{ws}} \frac{\mathrm{d} s}{\mathrm{~s}}+S_{\mathrm{r}} \mathrm{d} \varepsilon_{\mathrm{v}}=-\lambda_{\mathrm{ws}} n \frac{\mathrm{d} s}{\mathrm{~s}}+S_{\mathrm{r}} \mathbf{m}^{\mathrm{T}} \times \mathrm{d} \boldsymbol{\varepsilon}$

where $\mathbf{m}^{\mathrm{T}}=(1,1,1,0,0,0)$ and $n$ is the porosity of the soil. Note that in the equation above it is assumed that the volumetric strain of soil skeleton is due to the change to void volume only (i.e. the liquid water and solid particles are not compressible). The slope $\lambda_{\text {ws }}$ should be replaced by $\kappa_{\mathrm{ws}}$ for suction changes along the scanning curve.

Therefore, using the following notations

$\mathbf{D}^{\mathrm{ep}}=\mathbf{D}^{\mathrm{e}}-\frac{\mathbf{D}^{\mathrm{e}} \frac{\partial g}{\partial \overline{\boldsymbol{\sigma}}}\left(\frac{\partial f}{\partial \overline{\boldsymbol{\sigma}}}\right)^{\mathrm{T}} \mathbf{D}^{\mathrm{e}}}{\left(\frac{\partial f}{\partial \overline{\boldsymbol{\sigma}}}\right)^{\mathrm{T}} \mathbf{D}^{e} \frac{\partial g}{\partial \overline{\boldsymbol{\sigma}}}-\frac{\partial f}{\partial \bar{p}_{\mathrm{c}}} \frac{\partial \overline{p_{\mathrm{c}}}}{\partial \varepsilon_{\mathrm{v}}^{\mathrm{p}}} \frac{\partial g}{\partial \bar{p}}}$

$H=-\lambda_{\text {ws }} n / s$ or $H=-\kappa_{\text {ws }} n / s$

$\mathbf{W}^{\mathrm{ep}}=\frac{\mathbf{D}^{\mathrm{e}} \frac{\partial g}{\partial \overline{\boldsymbol{\sigma}}}\left(\frac{\partial f}{\partial \bar{p}_{0}} \frac{\partial \bar{p}_{0}}{\partial s}+\frac{\partial f}{\partial \bar{p}_{c}} \frac{\partial \bar{p}_{\mathrm{c}}}{\partial s}-\left(\frac{\partial f}{\partial \overline{\boldsymbol{\sigma}}}\right)^{\mathrm{T}} \mathbf{W}^{\mathrm{e}}\right)}{\left(\frac{\partial f}{\partial \overline{\boldsymbol{\sigma}}}\right)^{T} \mathbf{D}^{e} \frac{\partial g}{\partial \bar{\sigma}}-\frac{\partial f}{\partial \bar{p}_{c}} \frac{\partial \bar{p}_{c}}{\partial \varepsilon_{v}^{p}} \frac{\partial g}{\partial \bar{p}}}$

$\mathbf{T}=S_{\mathrm{r}} \mathbf{m}$ 
the final incremental stress-strain relationship can be written as

$$
\left(\begin{array}{c}
\mathrm{d} \boldsymbol{\sigma} \\
\mathrm{d} \theta
\end{array}\right)=\left(\begin{array}{ll}
\mathbf{D}^{\mathrm{ep}} & \mathbf{W}^{\mathrm{ep}} \\
T & H
\end{array}\right)\left(\begin{array}{l}
\mathrm{d} \varepsilon \\
\mathrm{d} s
\end{array}\right)
$$

where $\mathbf{D}^{\mathrm{ep}}$ is a $6 \times 6$ matrix, $\mathbf{T}$ is a row vector of 6 elements, $\mathbf{W}^{\mathrm{ep}}$ is a column vector of 6 elements, and $H$ is a scalar. The of strain rate and soil suction rate are both on the right-hand side, so the formulation is consistent with the displacement finite element method where pore pressures and displacements are first solved from equilibrium and continuity equations. The incremental stress-strain relationship defined by Eq. (37) can be implemented into the finite element method to solve boundary value problems.

\subsection{Global governing equations}

Constitutive models have to be implemented into numerical methods such as the finite element method to solve boundary value problems. The governing equations for unsaturated soils usually involve the equilibrium of momentum, the balance of mass and the balance of energy $[57,25,80,40,72]$. Under certain conditions, these equations can be simplified. For example, under isothermal condition, the heat transfer and the temperature field can be neglected. Moreover, under atmospheric air pressure, the flow of pore air can be neglected. Therefore, in the simplest form, the governing equations contain the equilibrium equation of momentum and the continuity equation of water flow. The equilibrium equation can be written in a weak form as

$\int_{V^{t}}\left(\partial \boldsymbol{\varepsilon}^{\mathrm{T}} \boldsymbol{\sigma}^{t}\right) \mathrm{d} V-\int_{S^{t}}\left(\partial \mathbf{u}^{\mathrm{T}} \mathbf{t}^{t}\right) \mathrm{d} S-\int_{V^{t}}\left(\partial \mathbf{u}^{\mathrm{T}} \mathbf{b}^{t}\right) \mathrm{d} V=0$

where $\delta \mathbf{u}$ is a virtual displacement field satisfying the displacement boundary conditions, $\delta \boldsymbol{\varepsilon}$ denotes the variation of the strain tensor, $\boldsymbol{\sigma}$ is the stress tensor, $\mathbf{b}$ is the body force vector, $\mathbf{t}$ is the distributed force acting on the boundary $S$ of the volume $V$, and the superscript $t$ stands for quantities that are measured at time $t$.

The continuity equation follows from the mass conservation of pore water and Darcy's law:

$\operatorname{div}\left(-\frac{\mathbf{k}}{\mathrm{g}}\left(\nabla u_{\mathrm{w}}-\mathbf{b}_{\mathrm{w}}\right)\right)+\frac{\partial}{\partial t}\left(\rho_{\mathrm{w}} \theta\right)=0$

where div is the divergence operator, $\mathbf{k}$ is the permeability tensor, $g$ is the gravity acceleration, $u_{\mathrm{w}}$ is the pore water pressure, $\mathbf{b}_{\mathrm{w}}$ is the body force vector of pore water, and $\rho_{\mathrm{w}}$ is the water density.

After appropriate spatial discretization the displacement and pore pressure fields can be approximated as

$\mathbf{u}=\mathbf{N} \mathbf{U}$

$U_{\mathrm{w}}=\mathbf{N}_{\mathrm{w}} \mathbf{U}_{\mathrm{w}}$

where $\mathbf{N}$ is the displacement shape function, $\mathbf{U}$ is the nodal displacement vector, $\mathbf{N}_{w}$ is the pore pressure shape function and $\mathbf{U}_{w}$ is the nodal pore pressure vector. The stress is updated incrementally:

$\sigma^{t}=\sigma^{t-\partial t}+\partial \sigma$

where $\sigma^{t-\partial t}$ is the stress at the last equilibrium state.

Now the constitutive equations must be incorporated into Eqs. (38) and (39). The finite element formulation may vary slightly, depending on the stress variables used in the constitutive equation. For example, if Eq. (37) is used, we have for zero air pressure:

$\left(\begin{array}{c}\mathrm{d} \boldsymbol{\sigma} \\ \mathrm{d} \theta\end{array}\right)=\left(\begin{array}{cc}\mathbf{D}^{\mathrm{ep}} & \mathbf{W}^{\mathrm{ep}} \\ T & H\end{array}\right)\left(\begin{array}{c}\mathrm{d} \varepsilon \\ -\mathrm{d} u_{\mathrm{w}}\end{array}\right)$

Eq. (43) can then be substituted into Eqs. (38) and (39). Due to the nonlinearity of the material behaviour, the governing equations are usually solved incrementally and the solution at time $t$ is sought with the known solution at time $t-\Delta t$. Therefore, the discretised finite element equations are usually written in rate form:

$\mathbf{K}^{\mathrm{ep}} \dot{\mathbf{U}}+\mathbf{L} \dot{\mathbf{U}}_{\mathrm{w}}=\dot{\mathbf{F}}^{\mathrm{ext}}$

$\mathbf{L}^{\prime} \dot{\mathbf{U}}+\dot{\mathbf{S U}}_{\mathrm{w}}+\dot{\mathbf{H}} \mathbf{U}_{\mathrm{w}}=\dot{\mathbf{Q}}^{\mathrm{ext}}$

where

$$
\begin{aligned}
& \mathbf{K}^{\mathrm{ep}}=\sum \int_{V^{e}}\left(\mathbf{B}^{T} \mathbf{D}^{\mathrm{ep}} \mathbf{B}\right) \mathrm{d} V^{e} \\
& \mathbf{L}=-\sum \int_{V^{e}}\left(\mathbf{B}^{T} \mathbf{W}^{\mathrm{ep}} \mathbf{N}_{\mathrm{w}}\right) \mathrm{d} V^{e} \\
& \dot{\mathbf{F}}^{\mathrm{ext}}=\sum\left(\int_{V^{e}}\left(\mathbf{N}^{T} \dot{\mathbf{b}}\right) \mathrm{d} V^{e}+\int_{S^{e}}\left(\mathbf{N}^{T} \dot{\mathbf{t}}\right) \mathrm{d} S^{e}\right) \\
& \mathbf{L}^{\prime}=\sum \int_{V^{e}} \rho_{\mathrm{w}}\left(\mathbf{N}_{w}^{T} \mathbf{T} \mathbf{B}\right) \mathrm{d} V^{e} \\
& \mathbf{S}=-\sum \int_{V^{e}} \rho_{\mathrm{w}}\left(\mathbf{N}_{w}^{T} H \mathbf{N}_{\mathrm{w}}\right) \mathrm{d} V^{e} \\
& \dot{\mathbf{H}}=\sum \int_{V^{e}}\left(\mathbf{B}_{w}^{T} \frac{\mathbf{k}}{g} \mathbf{B}_{\mathrm{w}}\right) \mathrm{d} V^{e} \\
& \dot{\mathbf{Q}}^{\text {ext }}=\left(-\sum \int_{S^{e}}\left(\mathbf{N}_{w}^{T} q^{t}\right) \mathrm{d} S^{e}-\sum \int_{V^{e}}\left(\mathbf{B}_{w}^{T} \frac{\mathbf{k}}{g} \mathbf{b}_{\mathrm{w}}\right) \mathrm{d} V^{e}\right)
\end{aligned}
$$

If Bishop's effective stress is used in the constitutive equations, i.e. Eq. (28), the definitions of the above matrices and vectors will change somewhat, but the governing equations will have the same form as (44) and (45). The discretised governing equations can also be written in a compact form of ordinary differential equations:

$\mathbf{C X}+\mathbf{K X}=\dot{\mathbf{W}}$

where $\mathbf{X}$ contains the global unknown nodal displacements and pore water pressures, $\mathbf{C}$ and $\mathbf{K}$ are coefficient matrices, $\mathbf{W}$ contains the external force and flow vectors, and the superior dot stands for the rate with respect to time.

Due to the material nonlinearity, Eq. (46) has to be solved numerically and appropriate algorithms have to be used at both the global and local levels. The global unknown $\mathbf{X}$ is usually solved step by step using a time integration scheme. For elasto-plastic consolidation problems it is usually recommended to use an implicit time stepping scheme, where the coefficient matrices are estimated at the time level where the unknown is sought and iterations are needed. Automatic time stepping schemes can be designed to control the integration error. More detailed discussion of time stepping schemes for consolidation problems can be found in $[89,74,68]$. Once the displacements and pore pressures are solved, the strains and suctions can be computed at Gauss points. The stresses and the volumetric water contents (or the degrees of saturations) are then solved from the constitutive relations, again numerically. A number of stress integration schemes are available in the literature, e.g. those by Sheng et al. [71], Sloan et al. [75], Sheng et al. [70] and Borja [11]. The following section discusses a specific challenge associated with Gauss point stress integration of unsaturated soil models, i.e. the problem of non-convex yield surfaces.

\subsection{Gauss point stress integration}

One of the main challenges in implementing an unsaturated soil model into finite element code arises from the non-convexity of the yield surface around the transition between saturated and unsaturated states. The non-convexity exists irrespective of the stress variables used in the model and is demonstrated in Fig. 12.

For given strain and suction increments, the current stress state and internal variables must be updated in accordance with Eq (28), (29). This update is generally carried out using numerical 


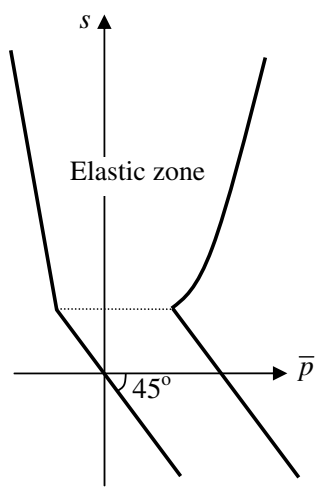

(a) net stress (Alonso et al. 1990)

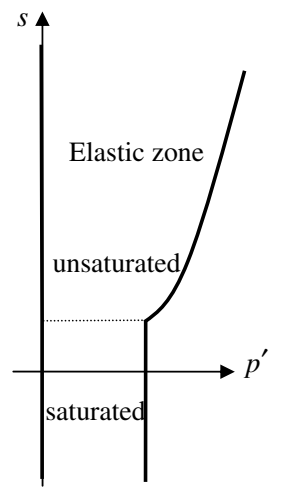

(b) effective stress (Sheng et al. 2003)

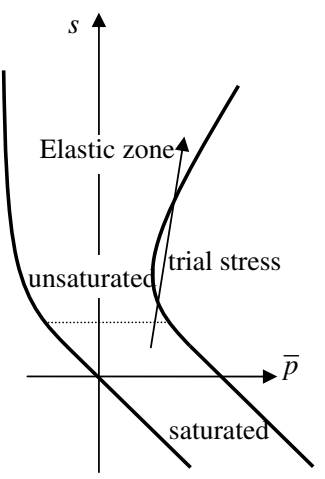

(c) net stress (Sheng et al. 2008a)

Fig. 12. Non-convexity of yield surfaces for unsaturated soils in a suction-stress space.

stress integration schemes. Both implicit and explicit schemes have been used to integrate elasto-plastic models. Implicit schemes, where all gradients are estimated at an advanced stress state, cannot be used for elasto-plastic models with non-convex yield surfaces, because the extrapolated gradients cannot be determined due to the uncertainty of whether an advanced position is inside or outside the yield surface. On the other hand, explicit schemes can proceed in an incremental fashion, but require the intersection between the current yield surface and an elastic trial stress path to be determined.

A key issue in integrating the incremental stress-strain relationships using an explicit method is thus to find the intersection between the elastic trial stress path and the current yield surface. The most complicated situation occurs when the yield surface is crossed more than once. However, it is not possible to know a priori how many times the yield surface is crossed, because the size of the yield surface will change after the first intersection due to hardening. Therefore, for non-convex yield surfaces, the key task is to find the very first intersection for any possible path.

In order to determine whether the yield surface is crossed, a secant trial stress increment is computed, based on an elastic stresssuction-strain relationship. This elastic trial stress is given as follows:

$\Delta \boldsymbol{\sigma}^{\mathrm{tr}}=\mathbf{D}^{\mathrm{e}}: \Delta \boldsymbol{\varepsilon}+\mathbf{W}^{\mathrm{e}} \Delta s$

where the stress is either the net stress or Bishop's effective stress (depending on the model), $\mathbf{D}^{\mathbf{e}}$ is the fourth order elastic stiffness tensor (in tensor notation) and $\mathbf{W}^{\mathrm{e}}$ is a second order tensor defined according to a specific law for unsaturated soils. For saturated soil models, the term $\mathbf{W} \Delta s$ depends on the stress variables used. If Bishop's effective stress is used, the term $\mathbf{W}^{\mathrm{e}} \Delta s$ becomes zero and can be disregarded. On the other hand, if the net stress is used, the term $\mathbf{W}^{\mathrm{e}} \Delta s$ becomes $-\mathbf{m} \Delta u_{w}$, where $\mathbf{m}$ is the second order identity tensor and $u_{\mathrm{w}}$ the pore water pressure.

In Eq. (47), $\Delta \varepsilon$ is the strain increment provided from the finite element routines prior to the computation of the residuals between internal and external forces. For unsaturated soils, the increment of suction $\Delta s$ is also input for the stress-update algorithm. If the elastic modulus is linear, i.e. it is independent of the stresses, suction and internal variables, it is trivial to compute the elastic trial increment. Otherwise, for some non-linear relations, a secant analytical modulus may be considered.

Finding the intersection between the elastic trial stress increment and the current yield surface can be cast as a problem of finding the multiple roots of a nonlinear equation. $f_{\alpha}(\alpha)=0$. The roots $(\alpha)$ must be computed inside the interval $[0,1]$. As this function involves the evaluation of the yield function along the strain and suction paths, it is given as $f_{\alpha}(\alpha)=f\left(\sigma_{\alpha}, s_{\alpha} \cdot z_{k}\right)$

where $\mathrm{f}\left(\boldsymbol{\sigma}, s, z_{k}\right)$ is the yield function, $z_{k}$ indicates a set of internal variables and the intermediate stress-suction states $\sigma_{\alpha}$ and $s_{\alpha}$ are calculated according to

$\boldsymbol{\sigma}_{\alpha}=\sigma_{\text {current }}+\alpha \Delta \boldsymbol{\sigma}^{\mathrm{tr}}$ and $s_{\alpha}=s_{\text {current }}+\alpha \Delta s$

in which $\boldsymbol{\sigma}_{\text {current }}$ and $s_{\text {current }}$ are the current stress and suction states. Note that in Eq. (48) the internal variables $z_{k}$ are kept constant during the solution for the intersection. These variables only change during hardening/softening when a portion of the trial stress-suction path is located outside the yield surface.

The technique proposed here follows the Kronecker-Picard (KP) formula for the determination of the number of roots of a nonlinear equation [39]. This formula, given by

$$
\begin{aligned}
N= & \frac{-\gamma}{\pi} \int_{a}^{b} \frac{f_{\alpha}(x) h_{\alpha}(x)-g(x)^{2}}{f_{\alpha}(x)^{2}+\gamma 2 g_{\alpha}(x)^{2}} \mathrm{~d} x \\
& +\frac{1}{\pi} \arctan \left\{\frac{\gamma\left(\left[f_{\alpha}(a) g_{\alpha}(b)-f_{\alpha}(b) g_{\alpha}(a)\right]\right)}{f_{\alpha}(a) f_{\alpha}(b)-\gamma^{2} g_{\alpha}(a) g_{\alpha}(b)}\right\}
\end{aligned}
$$

requires that $f_{\alpha}(\alpha)$ must be continuously or piecewise differentiable to the second order for values of $\alpha$ from $a$ to $b$. In Eq. (50), $g_{\alpha}$ and $h_{\alpha}$ represent the first and second derivatives of the function $f_{\alpha}$ with respect to $\alpha$, respectively, and $\gamma$ is a small positive constant which does not affect the results computed with the KP formula [39]. The first and second derivative of $f_{\alpha}$ with respect to $\alpha$ can be directly determined as follows:

$g_{\alpha}(\alpha)=\frac{\partial f_{\alpha}}{\partial \alpha}=\frac{\partial f_{\alpha}}{\partial \boldsymbol{\sigma}_{\alpha}}: \frac{\mathrm{d} \boldsymbol{\sigma}_{\alpha}}{\mathrm{d} \alpha}+\frac{\partial f_{\alpha}}{\partial s_{\alpha}} \frac{\mathrm{d} s_{\alpha}}{\mathrm{d} \alpha}=\left.\frac{\partial f}{\partial \boldsymbol{\sigma}}\right|_{\alpha}: \Delta \boldsymbol{\sigma}^{\mathrm{tr}}+\left.\frac{\partial f}{\partial s}\right|_{\alpha} \Delta s$

$h_{\alpha}(\alpha)=\frac{\partial^{2} f_{\alpha}}{\partial \alpha^{2}}=\Delta \boldsymbol{\sigma}^{\mathrm{tr}}:\left.\frac{\partial^{2} f}{\partial \boldsymbol{\sigma} \partial \boldsymbol{\sigma}}\right|_{\alpha}: \Delta \boldsymbol{\sigma}^{\mathrm{tr}}+\left.2 \Delta \sigma^{\mathrm{tr}} \frac{\partial^{2} f}{\partial \sigma \partial \sigma}\right|_{\alpha} \Delta s+\left.\frac{\partial^{2} f}{\partial s^{2}}\right|_{\alpha} \Delta s^{2}$

The number of roots estimated according to Eq. (50) is used to divide the interval of $\alpha$ into subintervals until each subinterval contains at most one root. First, $N$ is computed for the interval $[a, b]$. If $N$ is larger than one, the interval $[a, b]$ is divided into two equal subintervals, $[a,(a+b) / 2]$ and $[(a+b) / 2, b]$. The number of roots for each subinterval is then computed and any subinterval that contains more than one root is further divided into two equal sub- subintervals. This process continues until each subinterval contains at most one root. As shown by Kavvadias et al. [39], the use of equal-size intervals (equiprobable parts) is not much worse than an algorithm which would consider the statistical distribution of the roots inside $[a, b]$, such as the algorithm also presented in [39].

Once the roots are bracketed, the solution of each root can be found by using existing numerical methods such as the Newton- 

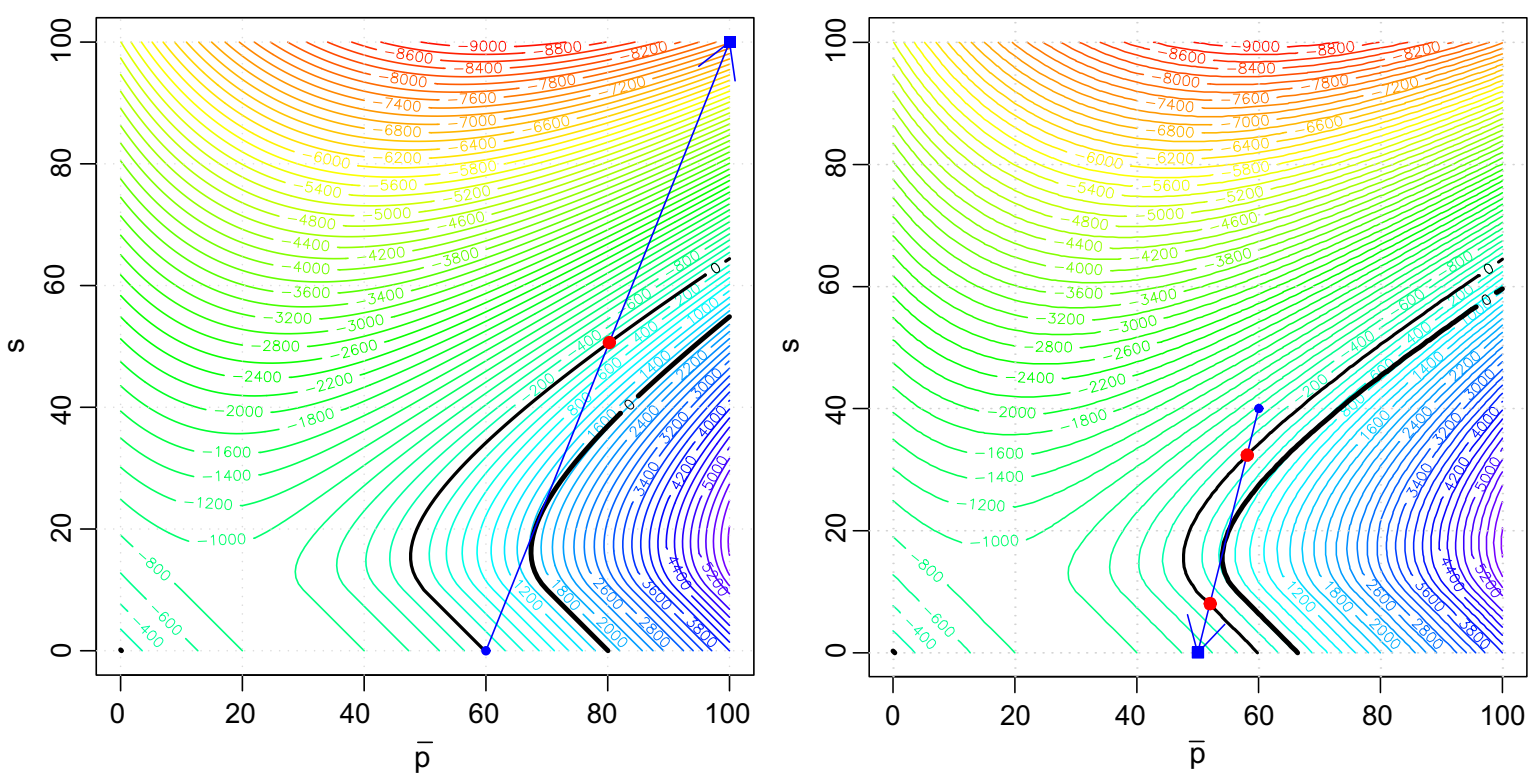

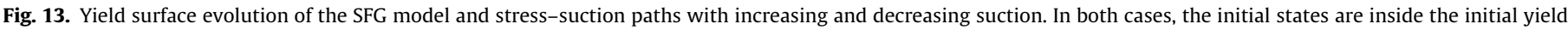
surfaces. The stress paths cross the initial yield surfaces twice $[66,67]$.

Raphson method. It should be noted that the Newton-Raphson method, although fast, may not converge in some circumstances because it does not constrain the solution to lie within specified bounds. Therefore, more advanced methods can be used here. For example, the Pegasus method used in [75] is very robust and competitively fast. The method of Brent [12] provides another attractive alternative. Brent's method does not use any derivatives, does not require initial guesses and guarantees convergence as long as the values of the function are computable within a given region containing a root. These characteristics of the Brent method follow from the fact that it is based on the bisection method, the secant method and inverse quadratic interpolation. Therefore, it has the reliability of the bisection method and the efficiency of the less reliable secant method and inverse quadratic interpolation.

The evaluation of the integral in Eq. (50) with the KP formula is generally not trivial and so a numerical integration or quadrature technique has to be used. For example, the Gauss-Legendre method can be used here. In addition, for highly non-linear yield functions, an adaptive integration scheme may also have to be used. Detailed information in this regard can be found in $[59,60,65,66]$. Fig. 13 demonstrates the stress integration along a stress path with increasing or decreasing suction. The stress paths start and end inside the initial yield surfaces and cross the initial yield surfaces twice. The explicit integration scheme is able to capture the intersection points correctly and to predict the evolution of the yield surface.

\section{Conclusions}

A number of conclusions can be drawn from this study:

1. The use of Bishop's effective stress for unsaturated soils can lead to a smooth transition between saturated and unsaturated states and simplified constitutive relations such as shear strength. However, the key issue is that the effective stress is usually not controllable in laboratory tests and its definition can depend on material states and even on stress path. Therefore, a constitutive relation established in such an effective stress space is less meaningful, since the stress space is constantly changing with the material state.
2. The use of net stresses for modelling unsaturated soils often leads to discontinuous models at the transition between saturated and unsaturated states. However, this problem can be avoided if a continuous volumetric stress-strain model is adopted.

3. A known constitutive model established in the net stress-suction space can be transformed to a Bishop-type effective stress-suction space. Such a transformation may simplify the mathematical expression of the constitutive relation and may avoid the discontinuity problem at the transition of saturated and unsaturated states.

4. Most elasto-plastic models have embodied shear strength criteria. In the SFG model, the friction angle $\phi^{\mathrm{b}}$ is a function of suction and the air entry value.

5. Hysteresis in the soil-water characteristic curves can be formulated in the same framework of elasto-plasticity, which leads to a consistent formulation of stress-strain and suction-saturation relations.

6. Unsaturated soil models inevitably have non-convex yield surfaces at the transition between saturated and unsaturated states. This non-convexity can significantly complicate the implementation of these models into finite element codes. An explicit stress integration scheme incorporating an efficient root search algorithm can be used to integrate an unsaturated soil model with a non-convex yield surface.

\section{References}

[1] Aitchison GD, Donald IB. Effective stresses in unsaturated soils. In: Proceedings of second Australian-New Zealand conference in soil mechanics; 1956. p. 192 9.

[2] Aitchison GD, Martin R. A membrane oedometer for complex stress-strain studies in expansive clays. In: Proceedings of third international conference on expansive soils, Haifa, Israel, vol. 2; 1973. p. 83-8.

[3] Alonso EE, Gens A, Hight DW. Special problem soils, general report. In: 9th European conference on soil mechanics, Dublin, vol. 3; 1987. p. 1087-146.

[4] Alonso EE, Gens A, Josa A. A constitutive model for partially saturated soils Géotechnique 1990;40(3):405-30.

[5] Alonso EE, Lloret A. Behaviour of partially saturated soil in undrained loading and step by step embankment construction. In: Proceedings of IUTAM conference on deformation and failure of granular materials, Delft, The Netherlands; 1982 . p. 173-80.

[6] Alonso EE, Vaunat J, Gens A. Modelling the mechanical behaviour of expansive clays. Eng Geol 1999;54:173-83. 
[7] Bao C, Gong B, Zhan L. Properties of unsaturated soils and slope stability of expansive soils, keynote lecture. In: Proceedings of the second international conference on unsaturated soils, UNSAT 98, Beijing, China, vol.1; 1998. p. 7198.

[8] Bishop AW. The principle of effective stress. Teknisk Ukeblad 1959;106(39):859-63.

[9] Bishop AW, Blight GE. Some aspects of effective tress in saturated and partly saturated soils. Géotechnique 1963;13:177-97.

[10] Bolzon G, Schrefler BA, Zienkiewicz OC. Elastoplastic soil constitutive laws generalised to partially saturated states. Géotechnique 1996;46(2):279-89.

[11] Borja RI. Cam clay plasticity, Part V: A mathematical framework for threephase deformation and strain localization analysis of partially saturated porous media. Comput Meth Appl Mech Eng 2004;193:5301-38.

[12] Brent RP. An algorithm with guaranteed convergence for finding a zero of a function. Comput J 1971;14:422-5.

[13] Chiu CF, Ng CWW. A state-dependent elasto-plastic model for saturated and unsaturated soils. Géotechnique 2003;53(9):809-29.

[14] Coleman JD. Stress strain relations for partly saturated soil. Géotechnique 1962;12:348-50.

[15] Cui YJ, Delage P. Yielding and plastic behaviour of an unsaturated compacted silt. Geotechnique 1996;46(2):291-311.

[16] Dangla P, Malinsky L, Coussy O. Plasticity and imbibition-drainge curves for unsaturated soils: a unified approach. In: Pietruszczak S, Pande GN, editors. Proceedings of 6th International Symposium on Numerical Models in Geomechanics - NUMOG, Balkema, Rotterdam; 1997. p. 141-6.

[17] Escario V, Jucá JFT. Strength and deformation of partly saturated soils. In: Proceedings of 12th international conference on soil mechanics and foundation engineering, Rio de Janeiro, vol. 1; 1989. p. 43-6.

[18] Fredlund DG, Morgenstern NR. Constitutive relations for volume change in unsaturated soils. Canad Geotech J 1976;13(3):261-76.

[19] Fredlund DG, Morgenstern NR. Stress state variables for unsaturated soils. J Geotech Eng Division, ASCE 1977;103(GT5):447-66.

[20] Fredlund DG, Morgenstern NR, Widger RA. The shear strength of unsaturated soils. Canad Geotech J 1978;15(3):313-21.

[21] Fredlund DG, Rahardjo H. Soil mechanics for unsaturated soils. New York: John Wiley \& Sons; 1993.

[22] Fredlund DG, Xing A. Equations for the soil-water characteristic curve. Canad Geotech J 1994;31(3):521-32.

[23] Fredlund DG, Xing A, Fredlund MD, Barbour SL. Relationship of the unsaturated soil shear strength to the soil-water characteristic curve. Canad Geotech J 1996;33(3):440-8.

[24] Gallipoli D, Gens A, Sharma R, Vaunat J. An elastoplastic model for unsaturated soil incorporating the effects of suction and degree of saturation on mechanical behaviour. Géotechnique 2003:53(1):123-35.

[25] Gawin D, Baggio P, Schrefler BA. Coupled heat water and gas flow in deformable porous media. Int J Num Meth Fluids 1995;20:969-87.

[26] Gens A. Constitutive modelling: application to compacted soils. In: Alonso EE Delage P, editors. Unsaturated soils, vol. 3. Rotterdam: Balkema; 1996. p. 1179-200.

[27] Gens A, Alonso EE. A framework for the behaviour of unsaturated expansive clays. Canad Geotech J 1992;29:1013-32.

[28] Gens A, Alonso EE, Josa A. Elastoplastic modelling of partially saturated soils, In: Pietruszczak $S$, Pande GN, editors. Proceedings of third international symposium on numerical models in geomechanics (NUMOG), Balkema, Rotterdam; 1989. p. 163-70.

[29] Gens A, Sánchez M, Sheng D. On constitutive modelling of unsaturated soils Acta Geotechnica 2006;1(3):137-47.

[30] Gens A, Guimarães L, Sánchez M, Sheng D. Developments in modelling the generalised behaviour of unsaturated soils. In: Toll et al., editors. Unsaturated soils: advances in geo-engineering. London: Taylor \& Francis Group; 2008. p. 53-61.

[31] Gardner R. Some steady state solutions of unsaturated moisture flow equation with application to evaporation from a water-table. Soil Sc 1958;85(4):228-32

[32] Hassanizadeh SM, Gray WG. General conservation equations for multiphase systems: 3 Constitutive theory for porous media flow. Adv Water Resour 1980;3:25-40.

[33] Hillel D. Soil and water - physical principles and processes. New York: Academic Press; 1971.

[34] Houlsby GT. The work input to an unsaturated granular material. Géotechnique 1997;47(1):193-6.

[35] Hutter K, Laloui L, Vulliet L. Thermodynamically based mixture models for saturated and unsaturated soils. Mech Cohes Frict Mat 1999;4:295-338.

[36] Jennings JEB, Burland JB. Limitations to the use of effective stresses in partly saturated soils. Géotechnique 1962;12(1):125-44.

[37] Jommi C. Remarks on the constitutive modelling of unsaturated soils. In: Tarantino A, Mancuso C, editors. Experimental evidence and theoretical approaches in unsaturated soils. Proceedings of international workshop on unsaturated soil, Balkema, Rotterdam; 2000. p. 139-53.

[38] Josa A, Balmaceda A, Gens A, Alonso EE. An elastoplastic model for partially saturated soil exhibiting a maximum of collapse. In: Owen DRJ, Onate E, Hinton E, editors. Computational plasticity III, vol. 1. Swansea: Pineridge Press; 1992. p. 815-26.

[39] Kavvadias DJ, Makri FS, Vrahatis MN. Locating and computing arbitrarily distributed zeros. SIAM J Scientific Comput 1999;21(3):954-69.
[40] Khalili N, Loret B. An elasto-plastic model for nonisothermal analysis of flow and deformation in unsaturated porous media: formulation. Int J Solids Struct 2001;38:8305-30.

[41] Kimoto S, Oka F, Fushita T, Fujiwaki M. A chemo-thermo-mechanically coupled numerical simulation of the subsurface ground deformations due to methane hydrate dissociation. Comput Geotech 2007;34(4):216-28.

[42] Kohgo Y, Nakano M, Miyazaki T. Theoretical aspects of constitutive modelling for unsaturated soils. Soils Foundat 1993;33(4):49-63.

[43] Kohler R, Hofstetter G. A cap model for partially saturated soils. Int J Numer Anal Meth Geomech; 2008. doi:10.1002/nag.658.

[44] Laloui L, Nuth M. On the use of the generalised effective stress in the constitutive modelling of unsaturated soils. Comput Geotech; 2008. doi:10.1016/i.compgeo.2008.03.002

[45] Lewis RW, Schrefler BA. The finite element method in the deformation and consolidation of porous media. Chichester: Wiley; 1987.

[46] Li XS. Effective stress in unsaturated soil: a microstructural analysis. Géotechnique 2003;53:273-7.

[47] Li XS. Modelling of hysteresis response for arbitrary wetting/drying paths. Comput Geotech 2005;32:133-7.

[48] Lins Y, Zou Y, Schanz T. Physical modeling of SWCC for granular materials. In: Schanz $T$, editor. Theoretical and numerical unsaturated soil mechanics. Germany: Springer, Weimer; 2007. p. 61-74.

[49] Loret B, Khalili N. An effective stress elastic-plastic model for unsaturated porous media. Mech Mater 2002;34:97-116.

[50] Lu N. Is matric suction a stress variable? J Geotech Geoenviron Eng, ASCE 2008;134(7):899-905.

[51] Matyas EL, Radhakrishna HS. Volume change characteristics of partially saturated soils. Géotechnique 1968;18:432-48.

[52] Modaressi A, Abou-Bekr N. A unified approach to model the behaviour of saturated and unsaturated soils. In: Eighth international conference on computer methods and advances in geomechanics (IACMAG), Balkema, Rotterdam; 1994. p. 1507-13.

[53] Morgenstern NR. Properties of compacted soils, In: Proceedings of the 6th PanAmerican conference on soil mechanics and foundation engineering. contribution to the panel discussion session IV, Lima, Peru, vol. 3; 1979. p. 349-354.

[54] Nuth M, Laloui L. Effective stress concept in unsaturated soils: clarification and validation of a unified framework. Int J Numer Anal Meth Geomech 2008;32(7):771-801.

[55] Oberg A, Salfors G. Determination of shear strength parameters of unsaturated silts and sands based on the water retention curve. Geotech Test J 1997;20:40-8.

[56] Oka F, Kodaka T, Kimoto S, Kim Y-S, Yamasaki N. An elastoviscoplastic model and multiphase coupled FE analysis for unsaturated soil. In: Proceedings of the fourth international conference on unsaturated soils, Geotechnical Special Publication (ASCE), No. 147, vol. 2; 2006. p. 2039-50.

[57] Olivella S, Carrera J, Gens A, Alonso EE. Nonisothermal multiphase flow of brine and gas through saline media. Transport Porous Media 1994;15:271-93.

[58] Pastor M, Zienkiewicz O, Chan A. Generalized plasticity and the modelling of soil behaviour. Int J Numer Anal Meth Geomech 1990;14:151-90.

[59] Pedroso DM, Sheng D, Sloan SW. Stress update algorithm for elastoplastic models with non-convex yield surfaces. Int J Numer Meth Eng; 2008. (Published online with doi:10.1002/nme.2407).

[60] Pedroso DM, Sheng D, Zhao JD. The concept of reference curves for constitutive modelling in soil mechanics. Comput Geotech; 2008. (Published online with doi:10.1016/j.compgeo.2008.01.009).

[61] Roscoe KH, Burland JB. On the generalised stress-strain behaviour of wet clay. In: Heyman J, Leckie F, editors. Engineering plasticity. Cambridge: Cambridge University Press; 1968. p. 535-60.

[62] Russell AR, Khalili N. A unified bounding surface plasticity model for unsaturated soils. Int J Numer Anal Meth Geomech 2006;30:181-212.

[63] Santagiuliana R, Schrefler BA. Enhancing the Bolzon-Schrefler-Zienkiewicz constitutive model for partially saturated soil. Transport Porous Media 2006;65(1):1-30.

[64] Sánchez M, Gens A, Guimarães L, Olivella S. A double structure generalized plasticity model for expansive materials. Int J Numer Anal Meth Geomech 2005;29:751-87.

[65] Sheng D, Fredlund DG, 2008, Elastoplastic modelling of unsaturated soils: an overview. In: Keynote paper to be presented at the 12th international conference of international association for computer methods and advances in geomechanics (IACMAG), 1-6 October, Goa, India; 2008.

[66] Sheng D, Fredlund DG, Gens A. A new modelling approach for unsaturated soils using independent stress variables. Canad Geotech J 2008;45(4):511-34.

[67] Sheng D, Pedroso DM, Abbo AJ. Stress path dependency and non-convexity of unsaturated soil models. Comput Mech. 2008b;42(5):685-695.

[68] Sheng D, Sloan SW. Time stepping schemes for coupled displacement and pore pressure analysis. Comput Mech 2003;31:122-34

[69] Sheng D, Sloan SW, Gens A. A constitutive model for unsaturated soils: thermomechanical and computational aspects. Comput Mech 2004;33(6):453-65.

[70] Sheng D, Sloan SW, Gens A, Smith DW. Finite element formulation and algorithms for unsaturated soils. Part I: Theory. Int J Numer Anal Meth Geomech 2003;27(9):745-65.

[71] Sheng D, Sloan SW, Yu HS. Aspects of finite element implementation of critical state models. Comput Mech 2000;26:185-96. 
[72] Sheng D, Smith DW, Sloan SW, Gens A. Finite element formulation and algorithms for unsaturated soils. Part II: Verification and application. Int J Numer Anal Meth Geomech 2003;27(9):767-90.

[73] Sheng D, Yao YP, Carter JP. A volumetric stress-strain model for sands allowing for the effects of particle crushing. Canad Geotech J 2008;45(12).

[74] Sloan SW, Abbo AJ. Biot consolidation analysis with automatic time stepping and error control. Part 1: Theory and implementation. Int J Numer Anal Meth Geomech 1999;23(6):467-92.

[75] Sloan SW, Abbo AJ, Sheng D. Refined explicit integration of elastoplastic models with automatic error control. Eng Comput 2001;18(1-2):121-54 [see also Erratum in Engineering Computation, 19, 594, 2002].

[76] Sun DA, Sheng D, Sloan SW. Elastoplastic modelling of hydraulic and stressstrain behaviour of unsaturated soil. Mech Mater 2007;39(3):212-21.

[77] Tamagnini R. An extended cam-clay model for unsaturated soils with hydraulic hysteresis. Géotechnique 2004;54(3):223-8.

[78] Tang GX, Graham J. A possible elastoplastic framework for unsaturated soils with high plasticity. Canad Geotech J 2002;39(4):894-907.

[79] Tarantino A, Tombolato S. Coupling of hydraulic and mechanical behaviour in unsaturated compacted clay. Geotechnique 2005;55(4):307-17.

[80] Thomas HR, He Y. An analysis of coupled heat, moisture and air transfer in a deformable unsaturated soil. Géotechnique 1995;45:667-89.
[81] Thu TM, Rahardjo H, Leong EC. Elastoplastic model for unsaturated soil with incorporation of the soil-water characteristic curve. Canad Geotech J 2007;44(1):67-77.

[82] Vaunat, J, Romero E and Jommi C. An elastoplastic hydromechanical model for unsaturated soils. In: Tarantino A, Mancuso C, editors. Experimental evidence and theoretical approaches in unsaturated soils. Proceedings of international workshop on unsaturated soil, Balkema, Rotterdam; 2000. p. 121-38.

83] Vanapalli SK, Fredlund DG, Pufahl DE. The influence of soil structure and stress history on the soil-water characteristics of a compacted till. Géotechnique 1999;44(2):143-59.

[84] Vanapalli SK, Fredlund DG, Pufahl DE, Clifton AW. Model for the prediction of shear strength with respect to soil suction. Canad Geotech J 1996:33:379-92.

[85] Van Guenuchten MT. A closed form equation of predicting the hydraulic conductivity of unsaturated soils. Soil Sci Am J 1980;44:892-8.

[86] Wheeler SJ, Karube D. Constitutive modelling, In: Alonso EE, Delage P, editors.Unsaturated soils, Balkema, Rotterdam, vol.3; 1996. p. 1323-56.

[87] Wheeler SJ, Sharma RS, Buisson MSR. Coupling of hydraulic hysteresis and stress-strain behaviour in unsaturated soils. Géotechnique 2003;53(1):41-54

[88] Wheeler SJ, Sivakumar V. An elasto-plastic critical state framework for unsaturated soil. Géotechnique 1995;45(1):35-53.

[89] Wood LW. Practical time stepping schemes. Oxford: Clarendon Press; 1990 